Document downloaded from:

http://hdl.handle.net/10251/82106

This paper must be cited as:

Martín Díaz, J.; Novella Rosa, R.; García Martínez, A.; Carreño-Arango, R.; Heuser, B.; Kremer, F.; Pischinger, S. (2016). Thermal analysis of a light-duty Cl engine operating with diesel-gasoline dual-fuel combustion mode. Energy. 115:1305-1319. doi:10.1016/j.energy.2016.09.021

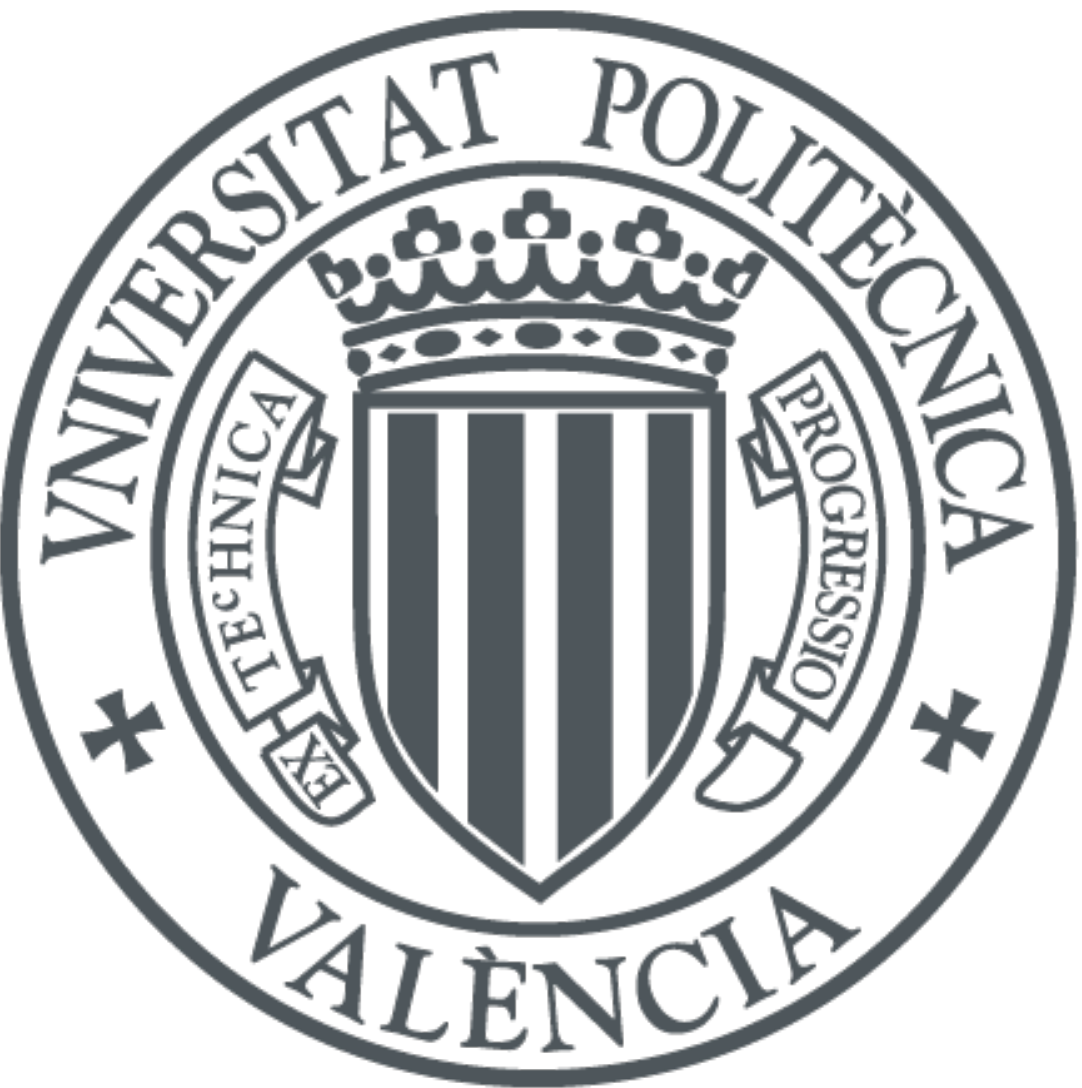

The final publication is available at

http://doi.org/10.1016/j.energy.2016.09.021

Copyright Elsevier

Additional Information 


\title{
Thermal analysis of a light-duty CI engine operating with Diesel-gasoline dual-fuel combustion mode
}

\author{
Jaime Martín ${ }^{\mathrm{a}, *}$, Ricardo Novella ${ }^{\mathrm{a}}$, Antonio García ${ }^{\mathrm{a}}$, Ricardo Carreño ${ }^{\mathrm{a}}$, Benedikt Heuser ${ }^{\mathrm{b}}$, Florian Kremer ${ }^{\mathrm{b}}$ \\ ${ }^{a}$ CMT-Motores Térmicos, Universitat Politècnica de València, Camino de Vera s/n, 46022, Valencia, Spain \\ ${ }^{b}$ Institute for Combustion Engines, RWTH Aachen University, Aachen, Germany
}

\begin{abstract}
The increasing awareness towards the high pollutant levels in the ambient and their effect in the human health, along with the progressively reduction of the non-renewable energy sources, have led to the research and development of new cleaner and more efficient engine strategies. In this sense, the premixed combustion modes show as highly efficient alternatives. Particularly, the Reactivity Controlled Compression Ignition (RCCI) points as one of the most efficient and clean strategies. Several works dealing with experimental and modelling assessment of the emissions/efficiency trade-off can be found in the literature; however, there is a lack of works dealing with a comprehensive thermal characterization of engines operating with RCCI mode. To contribute to this subject, an analysis of a single-cylinder engine operating with dual-fuel mode is presented in this work. A combined experimental and modelling Global Energy Balance (GEB) methodology is used, allowing the assessment of the energy degradation from the chemical energy release due to combustion, to the final work output. The relative weight of each term involved in the GEB is studied on two different basis: on the one hand, considering all the injected fuel energy, and on the other hand, taking into account only the burned fuel energy, thus decoupling the combustion and thermal processes. The effect of using a dual-fuel strategy in the GEB is studied by progressively increasing the low/high reactivity fuel ratio, thereby exploring the impact on combustion and thermal processes and evaluating the effect of switching from a diffusion controlled to a reactivity controlled combustion. Then, the efforts are focused on assessing the effect of the operating conditions, particularly the injection timing and EGR strategy. The results show an improvement in the indicated and thermal efficiencies about 1 and $4 \%$ when comparing with conventional Diesel combustion, explained by combustion improvement and reduction of heat transfer and exhaust losses.
\end{abstract}

Keywords: Consumption reduction, Dual-fuel, Energy balance, Heat transfer, RCCI

${ }^{*}$ Corresponding author. Tel: +34963877650 ; fax: +34963877659

Email address: jaimardi@mot.upv.es (Jaime Martín)

URL: www. cmt.upv.es (Jaime Martín) 


\section{Nomenclature}

$c_{p} \quad$ Specific heat at constant pressure $\ldots \ldots \ldots \ldots \ldots \ldots \ldots[\mathrm{J} / \mathrm{kgK}]$

$\dot{H}_{b b} \quad$ Blow-by sensible enthalpy flow $\ldots \ldots \ldots \ldots \ldots \ldots[W],\left[\% m_{f} H v\right]$

$\dot{H}_{g} \quad$ Net sensible enthalpy flow of exhaust gases $\ldots \ldots \ldots[W],\left[\% m_{f} H v\right]$

$\dot{H}_{i c} \quad$ Incomplete combustion energy term $\ldots \ldots \ldots \ldots \ldots[W],\left[\% m_{f} H v\right]$

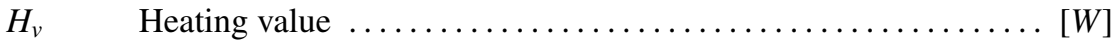

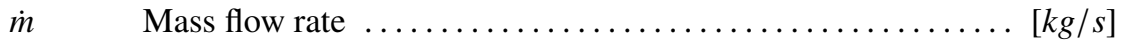

$N_{a} \quad$ Auxiliary power consumption $\ldots \ldots \ldots \ldots \ldots \ldots \ldots[W],\left[\% m_{f} H v\right]$

$N_{i} \quad$ Indicated power $\left.\ldots \ldots \ldots \ldots \ldots \ldots \ldots \ldots \ldots \ldots \ldots \ldots \ldots \ldots \ldots m_{f} H v\right]$

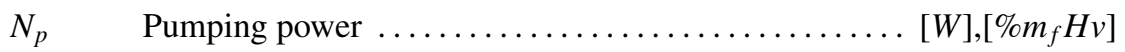

$H R_{\max } \quad$ Maximum cumulative heat release $\left.\ldots \ldots \ldots \ldots \ldots \ldots \ldots \ldots\right]$

$\eta_{b} \quad$ Brake efficiency $\ldots \ldots \ldots \ldots \ldots \ldots \ldots \ldots \ldots \ldots \ldots \ldots \ldots \ldots \ldots \ldots \ldots \ldots \ldots$

$\eta_{i} \quad$ Indicated efficiency $\ldots \ldots \ldots \ldots \ldots \ldots \ldots \ldots \ldots \ldots \ldots \ldots \ldots \ldots \ldots \ldots$

$\eta_{t h} \quad$ Thermal efficiency $\ldots \ldots \ldots \ldots \ldots \ldots \ldots \ldots \ldots \ldots \ldots \ldots \ldots \ldots \ldots \ldots$

$p \quad$ In-cylinder pressure $\ldots \ldots \ldots \ldots \ldots \ldots \ldots \ldots \ldots \ldots \ldots \ldots \ldots \ldots \ldots \ldots \ldots \ldots \ldots$

$\dot{Q}_{\text {cool }} \quad$ Heat transfer to the coolant $\ldots \ldots \ldots \ldots \ldots \ldots \ldots \ldots[W],\left[\% m_{f} H v\right]$

$\dot{Q}_{E G R} \quad$ Heat transfer to the EGR cooler $\ldots \ldots \ldots \ldots \ldots \ldots \ldots[W],\left[\% m_{f} H v\right]$

$\dot{Q}_{e x t} \quad$ Heat transfer to the ambient $\ldots \ldots \ldots \ldots \ldots \ldots \ldots[W],\left[\% m_{f} H v\right]$

$\dot{Q}_{\text {oil }} \quad$ Heat transfer to the oil $\left.\ldots \ldots \ldots \ldots \ldots \ldots \ldots \ldots \ldots \ldots \ldots \ldots m_{f} H v\right]$

$\dot{Q}_{t o t} \quad$ Total heat transfer $\left.\ldots \ldots \ldots \ldots \ldots \ldots \ldots \ldots \ldots \ldots \ldots \ldots \ldots m_{f} H v\right]$

$\dot{Q}_{\text {unbal }} \quad$ Unbalance energy term $\left.\ldots \ldots \ldots \ldots \ldots \ldots \ldots \ldots \ldots \ldots \ldots m_{f} H v\right]$

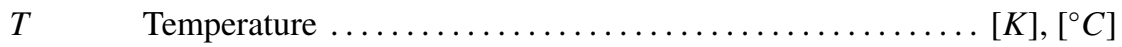

$\tau_{E G R} \quad$ Rate of exhaust gases recirculated $\ldots \ldots \ldots \ldots \ldots \ldots \ldots \ldots \ldots \ldots$

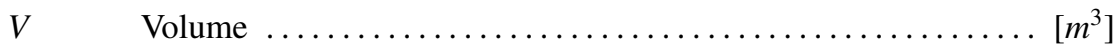




\begin{tabular}{|c|c|}
\hline Abbreviations & \\
\hline $\mathrm{ACE}$ & Apparent Combustion Efficiency \\
\hline ARC & Active Radical Combustion \\
\hline $\mathrm{CDC}$ & Conventional Diesel Combustion \\
\hline $\mathrm{CI}$ & Compression Ignition \\
\hline $\mathrm{CO}$ & Carbon monoxide \\
\hline $\mathrm{CO}_{2}$ & Carbon dioxide \\
\hline $\mathrm{CR}$ & Compression Ratio \\
\hline DI & Direct Injection \\
\hline EGR & Exhaust Gases Recirculation \\
\hline EU & European Union \\
\hline GEB & Global Energy Balance \\
\hline HCCI & Homogeneous Charge Compression Ignition \\
\hline HR & Cumulative heat released \\
\hline$H C$ & hydrocarbon \\
\hline HT & Heat Transfer \\
\hline ICE & Internal Combustion Engine \\
\hline IVC & Intake Valve Closing \\
\hline LTC & Low Temperature Combustion \\
\hline MK & Modulate Kinetics \\
\hline MSE & Mean Squared Error \\
\hline$N O_{x}$ & Nitrogen oxide \\
\hline PCCI & Premixed Charge Compression Ignition \\
\hline PFI & Port Fuel Injection \\
\hline PM & Particulate Matter \\
\hline RCCI & Reactivity Controlled Compression Ignition \\
\hline RoHR & Rate of Heat Release \\
\hline SoI & Start of Injection \\
\hline TDC & Top Dead Centre \\
\hline $\mathrm{VCV}$ & Volume control valve \\
\hline
\end{tabular}




\section{Introduction}

The increasing awareness towards the high pollutant levels in the ambient due to their effects on the human health and climatic change, along with the progressively reduction of the non-renewable energy sources, have led to a more stringent emissions regulation and focused the interest on reducing fossil fuels consumption. Taking into account these health and environmental issues, the European Union (EU) has defined the European emission standards (Euro 1 to 6) that new vehicles sold in the European territory must comply, in which the emissions of Nitrogen oxide $\left(N O_{x}\right)$ and Particulate Matter (PM) allowed limits are drastically reduced. Moreover, it is expected that the upcoming regulations set stringent limits for allowed fleet Carbon dioxide $\left(\mathrm{CO}_{2}\right)$ emissions, being necessary the increase of Internal Combustion Engines (ICE) efficiency. In this regard, the first international commitments have appeared into scene [1].

Currently, $N O_{x}$ and PM are actively controlled in Conventional Diesel Combustion (CDC)[2] by means of optimized injection strategies [3], high injection pressure [4], high boost pressure [5], high swirl [6] and tumble ratios [7], Exhaust Gases Recirculation (EGR) [8], variable valve timing [9] or cleaner fuels [10] among others. In spite of these efforts, to comply with the current and the upcoming regulations, the use of after treatment systems is being a necessary practice in the automotive industry [11]. However, such systems allows reaching the legislation goals with a penalty of engine efficiency. Since significant CDC improvements are barely attainable, the research on alternative combustion concepts is drawing the automotive sector's attention.

To reach both higher efficiencies and low $N O_{x}$ and soot emissions, the optimization of the air-fuel mixing process is mandatory to attain high burning rates while keeping Low Temperature Combustion (LTC). This can be achieved by homogeneous premixed charge of air, fuel and residual gases burned by means of a Compression Ignition (CI) strategy. This combustions modes are known as Homogeneous Charge Compression Ignition (HCCI), whose benefits and drawbacks have been widely reported [12]. The precise control of pressure and temperature required for a proper autoignition besides the complex homogeneous charge preparation, limit the HCCI strategy to a narrow operating range and result in long warm-up periods and high Hydrocarbons $(H C)$ and Carbon monoxide $(C O)$ emissions levels [13]. To overcome these issues, several variations of the HCCI concept have been proposed, such as: Premixed Charge Compression Ignition (PCCI) [14], Active Radical Combustion (ARC) [15] and Modulate Kinetics (MK) [16]. In these concepts, new air management, fuel injection and mixture formation strategies are used to extend the operating range and to reduce pre-ignition, knocking and $H C$ emissions. These methods have in common that they try to reduce the charge reactivity through the reduction of the mixture temperature, thus slowing down the chemical reactions and delaying the autoignition $[17,18]$. The control of the charge reactivity by in-cylinder blending of a separately injected low and high reactivity fuels to achieve reactivity stratification along the chamber, called Reactivity Controlled Compression Ignition (RCCI), has been studied as a solution of most of the problems presented by the previous modes while achieving high engine efficiency $[19,20]$. The benefits of the RCCI concept regarding $N O_{x}$ 
and PM emissions reduction have been broadly reported [21, 22, 23]; however, few works include a detailed energy analysis of the engine to characterize its degradation during RCCI operation, which is crucial for understanding the mechanism allowing the high efficiency of this combustion mode.

The Global Energy Balance (GEB) [24] arises as a useful methodology to identify the paths followed by the chemical energy of the fuel. The identification of the energy flow paths allows determining the energy losses caused by different processes inherent to ICE operation such as cooling and lubricating among others. Therefore, the engine thermal performance can be evaluated to identify further development alternatives. Depending on the specific application, different definitions of the GEB can be found in the literature: in the most general approach, the GEB can be performed taking into account the brake power, the Heat Transfer (HT) and the exhaust enthalpy losses. However, in the most complete experimental works, the HT to the coolant, oil, air, ambient [25], EGR and miscellaneous losses [24] are specifically considered. Similarly, some modelling-based approaches, which range from the combustion chamber [26] and the cooling system [27] analysis to the complete engine sub-systems simulation [28] can be also found. The combined use of such experimental and modelling tools is desirable to conduct a comprehensive and reliable GEB analysis, since it allows both, performing a deeper analysis of the energy use and validating the accuracy of the calibrated HT sub-models [29].

For these reasons, this work deals with the experimental/modelling GEB of a single-cylinder engine operating with dual-fuel, in which the effects of the low/high reactivity fuel ratio, the Start of Injection (SoI) and the EGR rate on the GEB are evaluated. To achieve a complete insight of the RCCI concept potential, a comprehensive comparison between dual-fuel and CDC at comparable power output and emissions levels is carried out, approaching from a diffusion combustion to a RCCI one. The GEB is compared in terms of both, the total input fuel energy and the effective burned fuel energy (eliminating the effect of incomplete combustion) to allow a fair comparison and enrich the analysis through decoupling of the combustion and thermal processes.

\section{Experimental setup}

The engine used for this study is a single-cylinder research engine with a displacement of $0.39 l$. The engine is equipped with two injection systems, one for Diesel Direct Injection (DI) and one for gasoline Port Fuel Injection (PFI), thus allowing dual-fuel operation. The DI is a state of the art system near to series production and reach an injection pressure up to 2200 bar. For the PFI, a series production Bosch valve was used. The engine control unit is based on a rapid control prototyping computer enabling a free determination of the injection parameters for both DI and PFI. The engine features a maximum specific power output of $80 \mathrm{~kW} / \mathrm{l}$ with peak firing pressures up to $190 \mathrm{bar}$. Thanks to intense intake air and EGR cooling, the engine meets EU6.1 $N O_{x}$ level whilst simultaneously achieving 
low particulate matter (PM) emissions even in CDC operation. For dual-fuel operation, apart from the addition of the PFI system the engine geometry was not modified. Therefore, the piston has an $\omega$-shaped re-entrant bowl with a volume of $21.6 \mathrm{~cm}^{3}$, a squish height of $0.78 \mathrm{~mm}$ and the nominal compression ratio (CR) is $15: 1$. The main engine specifications are given in Table 1 and a more detailed description of the engine can be found in [30].

Regulated and unregulated emissions are measured at exhausts by means of the dedicated equipment presented in Table 2. The sampling lines are heated up to $180^{\circ} \mathrm{C}$ for the $H C, C O$, and $N O_{x}$ measurements to avoid condensation. The sample line of the Smoke Meter is heated to $75^{\circ} \mathrm{C}$. The EGR rate is calculated based on the molecular $\mathrm{CO}_{2}$ concentration at the intake manifold and the exhaust gas line. The fuel consumption of both gasoline and Diesel fuel is measured by means of a Coriolis-type fuel flow meter. An ultrasonic gas meter is used to measure the volumetric air flow. Taking into account the air temperature and its water content the air mass flow is calculated. The boost pressure can be adjusted independently by an external three-stage charging system which also provides low intake air temperatures via three charge air coolers connected in series. An electric position-controlled EGR valve is used for adjusting the EGR rate. The exhaust gas back-pressure is controlled with two valves located at the exhaust gas line. A water cooled piezoelectric pressure transducer Kistler 6041A is used to measure the in-cylinder pressure. FEV's Combustion Analysing System records the in-cylinder pressure trace, where all pressures are recorded at angular increments of $0.5^{\circ}$ except the in-cylinder pressure, which is recorded at $0.1^{\circ}$. The digital processing was performed following the method described in [31] and the calculation of burning rates, mass fraction burned, ignition delay, energy terms, etc. was performed by means of an in-home developed software called CALMEC [29, 32].

This study focuses on the application of a dual-fuel approach for a light duty engine as it is used for passenger cars. Therefore, almost the whole engine load regime was previously investigated and calibrated in CDC, covering low part load operation to full load operation [30, 33]. For the initial characterization of dual-fuel operation, most of the operating parameters such as boost pressure, DI rail pressure, and combustion phasing (CA50) were kept constant at part load operation. Regarding the fuels used in this work, conventional EN228 gasoline RON95 E10 was selected as low reactivity fuel (PFI), while standard EN590 Diesel pump fuel was chosen as high reactivity fuel (DI). The physical characteristics of the fuels are given in Table 3.

In this work, the experiments are performed at 3 part load operating conditions, denoted as A1 to A3 for convenience. The main operation settings of these part load points are summarized in Table 4, and correspond to the nominal settings that will be kept constant in both, the calibration phase and the dual-fuel operation. 


\section{Methodology}

\subsection{Global energy balance description}

It is important to define the GEB for the case of a single-cylinder engine, taking into account that the sub-systems can significantly vary from those of a production multi-cylinder engine. As an example, the coolant and lubricating fluids are usually externally pumped, the fuel and air conditioning carried out in special external devices and the turbo charging conditions simulated by compressing the intake air and generating back-pressure at the exhaust by means of valves. Taking these characteristics into account, a common scheme of the energy balance for a single-cylinder engine is presented in Figure 1. This scheme shows most of the energy interactions occurring during the engine operation, considering the main energy inputs and final outputs (energy terms outside the dashed line) and the internal interactions (inside the dashed line). According to [29], the considered terms can be determined as:

$-\dot{m}_{f} H_{v}$ : it is the input fuel energy, determined from the fuel mass flow measurement and the lower heating value obtained through chemical characterization of the fuel, included in Table 3.

$-N_{i}, N_{p}$ : they are the gross indicated and the pumping powers, which are estimated through the integration of the $p-V$ diagram between the intake and exhaust bottom dead centres [34].

- $N_{b}, N_{a}, N_{f r}$ : they are brake power, the auxiliary and friction losses respectively. The brake power is estimated from the engine speed $(n)$ and torque $(M)$ as:

$$
N_{b}=2 \pi M n
$$

and $N_{a}$ and $N_{f r}$ are determined together from indicated, pumping and brake powers as:

$$
N_{a}+N_{f r}=N_{i}+N_{p}-N_{b}
$$

- $\dot{m}_{a} h_{a}^{\text {sens }}, \dot{m}_{f} h_{f}^{\text {sens }}, \dot{m}_{e x h} h_{\text {exh }}^{\text {sens }}$ : they are the air, fuel and exhaust sensible enthalpies, determined from the air and fuel mass flow measurement and from the sensible specific enthalpies defined as:

$$
h_{i}^{\text {sens }}=\int_{T_{0}}^{T_{i}} c_{p, i} d T
$$

where $i$ refers to the air, fuel or exhaust respectively, $T_{0}=25^{\circ} \mathrm{C}$ is the reference temperature and $T_{i}$ is the temperature at which the enthalpy is calculated. The exhaust mass flow $\left(\dot{m}_{e x h}\right)$ is determined as the addition of the air an fuel flow rates.

- $\dot{Q}_{\text {cham,cool }}, \dot{Q}_{\text {cham,oil }}, \dot{Q}_{\text {ports }}:$ they are the HT from chamber to the coolant and the oil and the HT to the ports respectively. They are determined by means of convective HT models and a lumped conductance model, whose details can be found in [29]. 
- $\dot{Q}_{E G R}:$ it is the heat loss in the EGR cooler, determined through the enthalpy difference between EGR cooler inlet and outlet:

$$
\dot{Q}_{E G R}=\dot{m}_{E G R} c_{p, E G R}\left(T_{E G R, o u t}-T_{E G R, \text { in }}\right)
$$

where $T_{E G R \text {, in }}$ and $T_{E G R}$,out are the EGR temperatures measured at the cooler inlet and outlet, $c_{p, E G R}$ is the specific heat of the burned gases and $\dot{m}_{E G R}$ is the EGR mass flow, obtained from the EGR rate $\left(\tau_{E G R}\right)$ :

$$
\dot{m}_{E G R}=\dot{m}_{a}\left(\frac{\tau_{E G R}}{1-\tau_{E G R}}\right)
$$

- $\dot{H}_{i c}$ : it is the energy losses due to incomplete combustion, which are determined by considering the $H C, C O$ and soot emissions:

$$
\dot{H}_{i c}=\left(Y_{H C} H_{v, H C}+Y_{C O} H_{v, C O}+Y_{C} H_{v, C}\right) \dot{m}_{e x h}
$$

where $Y_{H C}, Y_{C O}$ and $Y_{C}$ are the mass fractions of $H C, C O$ and soot, while $H_{v, H C}, H_{v, C O}$ and $H_{v, C}$ are their lower heating values respectively.

The use of experimental and modelling sources to determine the energy terms requires the suitable definition of the energy balance, which is presented in. Equation (7):

$$
\dot{m}_{f} H_{v}=N_{i, n e t}+\dot{Q}_{\text {cham }}+\dot{Q}_{\text {ports }}+\dot{H}_{g}+\dot{Q}_{E G R}+\dot{H}_{i c}+\dot{Q}_{\text {unbal }}
$$

where $N_{i, \text { net }}$ is the net indicated power calculated as presented in Equation (8), $\dot{Q}_{\text {cham }}$ is the HT from chamber to coolant and oil $\left(\dot{Q}_{\text {cham,cool }}+\dot{Q}_{\text {cham,oil }}\right), \dot{H}_{g}$ is the net flow of sensible enthalpy of exhaust gases, determined through an enthalpy balance between intake (before air and EGR mixing) and exhaust line after the EGR extraction (see Equation (9)) and $\dot{Q}_{\text {unbal }}$ is the unbalance term accounting for the experimental and modelled uncertainty as well as for minor terms such as the blow-by.

$$
\begin{gathered}
N_{i, n e t}=N_{i}+N_{p}=N_{b}+\left(N_{a}+N_{f r}\right) \\
\dot{H}_{g}=\dot{m}_{e x h} h_{e x h}^{\text {sens }}-\dot{m}_{a} h_{a}^{\text {sens }}-\dot{m}_{f} h_{f}^{\text {sens }}
\end{gathered}
$$

It is convenient to express Equation (10) in terms of the total input fuel energy percentage $\left(\% \dot{m}_{f} H_{v}\right)$ as:

$$
100 \% \dot{m}_{f} H_{v}=\eta_{i, \text { net }}+\Theta_{\text {cham }}+\Theta_{\text {ports }}+\Theta_{g}+\Theta_{E G R}+\Theta_{i c}+\Theta_{\text {unbal }}
$$


where $\eta_{i, n e t}$ is the net indicated efficiency, $\Theta_{\text {cham }}, \Theta_{\text {ports }}, \Theta_{E G R}$ are the percentage of HT to the chamber, the ports and the EGR and $\Theta_{g}, \Theta_{i c}, \Theta_{\text {unbal }}$ are the percentage of exhaust losses, incomplete combustion and unbalance terms.

The study performed is oriented to the thermal characterization of a research engine operating with dual-fuel; thus, some considerations must be done in order to better analyse the representative thermal terms:

- Although $N_{i, \text { net }}$ must be considered in Equation (7) to perform the GEB, from the performance point of view, dual-fuel combustion is better evaluated through the gross indicated power $\left(N_{i}\right)$, since the analysis of the pumping work in a research single-cylinder engine could mislead the conclusions.

- In CDC, the unburned fuel energy is usually lower than $1 \% \dot{m}_{f} H_{v}$; however, this term gains relevance in dualfuel operation and can reach levels about $9 \% \dot{m}_{f} H_{v}$ [20]. This high incomplete combustion losses are associated with lower combustion efficiency $\left(\eta_{c o m b}\right)$, which is explained mainly by the unburned fuel trapped in crevices and flame quenching near the walls [23]. It has been reported that, with the proper design of the combustion chamber (piston shape optimization and crevice reduction), the combustion efficiency of HCCI [35] and RCCI [36] modes can be improved to values near $100 \% \dot{m}_{f} H_{v}$. To carry out a fair comparison between dual-fuel and CDC modes and taking into account that the engine used in this work is a conventional Diesel one, it is convenient to decouple the combustion and thermal processes. For this reason, the thermal efficiency $\left(\eta_{t h}\right)$ is used as an indicator of the thermal fuel-to-work conversion performance, since it only considers the burned fuel as presented in Equation (11):

$$
\eta_{t h}=\frac{\eta_{i}}{\eta_{\text {comb }}}
$$

where $\eta_{\text {comb }}$ is defined as the ratio between the chemical energy of the injected fuel and the heat release due to the fuel burning $\left(\dot{m}_{f}^{\text {bur }} H_{v}\right)$ and can be calculated from the exhaust emissions as:

$$
\eta_{c o m b}=\frac{\dot{m}_{f}^{\text {bur }} H_{v}}{\dot{m}_{f} H_{v}} \approx\left(1-\frac{H C}{\dot{m}_{f}}-\frac{C O}{4 \dot{m}_{f}}\right)
$$

- In order to keep the coherence through the GEB analysis, all the energy terms considered should be compared over the same basis. Thus, a variation of the GEB is obtained by rearranging terms in Equation (10) and dividing by $\eta_{\text {comb }}$ :

$$
100 \% \dot{m}_{f}^{\text {bur }} H_{v}=\eta_{t h}+\Theta_{\text {cham }}^{\text {th }}+\Theta_{\text {ports }}^{\text {th }}+\Theta_{g}^{t h}+\Theta_{E G R}^{t h}+\Theta_{\text {unbal }}^{\text {th }}
$$

where the superscript th is used to indicate that the energy terms are in relative terms of the burned fuel.

The terms presented in Equation (13) are indicators of the thermodynamic process independently of the combustion efficiency, thereby being complementary to the GEB definition presented in Equation (10). 


\section{GEB and combustion analysis tool}

CALMEC $[29,32]$ is the thermodynamic tool used to perform the combustion analysis, calculate the instantaneous evolution of in-cylinder properties of the gas and model the energy terms involved in the GEB. The model considers all the relevant engine sub-systems through the combination of both physical and semi-empirical sub-models to calculate the heat transfer flow to combustion chamber walls and ports, mechanical losses and intake and exhaust processes. The main assumptions in the model are:

- Chamber pressure and temperature are assumed to be spatially uniform.

- Three species (air, fuel vapour and stoichiometric combustion products) are considered [37].

- Ideal gas law is used to calculate mean gas temperature.

- A filling and emptying model is used to calculate the trapped mass [38].

- Specific heat of the gas depends on both temperature and composition [39].

- Blow-by model is based on the evolution of the gas in an isentropic nozzle [38].

- Chamber volume deformation is calculated by means of a simple deformation model [40].

- Heat transfer to the chamber walls is calculated with a modified Woschni-like model [41].

- A lumped conductance model was used to calculate wall temperatures in the chamber and ports along with the heat rejection to coolant and oil. The model consists of 102 nodes in the cylinder head, 66 in the liner, 10 in the piston and some boundary nodes that take into account the oil, coolant, fresh air, in-cylinder gas, and intake and exhaust gases [29].

Since CALMEC was originally developed for CDC, some modifications and assumptions are necessary to make the tool suitable for dual-fuel operation. By solving the first law of thermodynamics, the following expression to determine the Rate of Heat Released (RoHR) can be obtained [37]:

$$
\begin{aligned}
\text { RoHR } & =\frac{\mathrm{dHR}}{\mathrm{d} \alpha} \\
& =m c_{v} \frac{\mathrm{d} T}{\mathrm{~d} \alpha}+\frac{\mathrm{d} Q}{\mathrm{~d} \alpha}+p \frac{\mathrm{d} V}{\mathrm{~d} \alpha}-\left(h_{f, i n j}-u_{f, g}\right) \frac{\mathrm{d} m_{f, e v}}{\mathrm{~d} \alpha}+R_{c} T_{c} \frac{\mathrm{d} m_{b b}}{\mathrm{~d} \alpha}
\end{aligned}
$$

where $m$ is the instantaneous mass calculated from the trapped mass at the IVC (obtained by means of a filling and emptying model [38]) and taking into account the cumulated blow-by leakage, $c_{v}$ is the specific heat calculated taking into account the instantaneous temperature and composition of the charge, $h_{f, i n j}$ and $u_{f, g}$ are the injected fuel enthalpy and the evaporated fuel internal energy and $R$ is the ideal gas constant, $\mathrm{d}_{m f, e v}$ is the variation of fuel injected and $\mathrm{d}_{m b b}$ 
is the variation of blow-by leakage respectively.

In Equation (14) all the involved phenomena can be easily identified: in the left-hand side $\mathrm{d} H R / \mathrm{d} \alpha$ is the heat released by combustion in a calculation step, whereas the terms in the right-hand side are, from left to right, the sensible internal energy of the gas, the heat transfer to the walls, the work done by the gas, the energy required for the fuel injection, evaporation and heating, and the flow work associated with the blow-by leakage. This equation is directly applicable in CDC but some comments have to be done before use it in dual-fuel applications:

- The port fuel injection is modelled as a direct injection during the intake process, thus obtaining a homogeneous mixture of air and fuel in the chamber at the IVC.

- Since the model considers just one zone in the chamber, only gas phase is considered and the injected fuel is assumed to be instantaneously evaporated during closed cycle.

- The fuel is considered as a blend of gasoline and Diesel. This simplification was be made because the model considers only one zone, therefore, it is not possible to handle separate combustion processes. Since the relevant combustion information is retained in the instantaneous pressure trace, i.e. $p(\alpha)$, this assumption does not represent an important uncertainty.

It is important to highlight that the $p(\alpha)$ and some mean values (mean temperatures and mass flows) are the main inputs and retain the combustion and thermal information, thus the uncertainty due to evaporation process inaccuracies and gas properties is expected to be similar as in a CDC.

In order to get accurate information from the GEB tool and to reduce the effect of some uncertainties, a calibration of the tool sub-models was performed. The calibration process following presented consist of two phases: the engine/installation uncertainties characterization using motoring tests, and the determination of the fitting constants of the HT model in combustion operation.

\subsection{Uncertainties characterization}

An initial adjustment of engine/installation parameters was carried out to assure accurate estimation of the HT terms, specially in the combustion chamber. For this objective, tests in motoring conditions were used to adjust some uncertainties (i.e. CR, TDC position and the constant of the deformation model) along with the $C_{w 1}$ and $C_{w 2}$ constants of the Woschni-like model [41] presented in Equation (15).

$$
h=C D^{-0.2} p^{0.8} T^{0.55}\left[C_{w 1} c_{m}+C_{w 2} c_{u}+C_{2} \frac{V_{d} p_{I V C}}{V_{I V C} T_{I V C}}\left(p-p_{0}\right)\right]^{0.8}
$$

where $h$ is the heat transfer coefficient, $D$ is the cylinder bore, $p$ is the in-cylinder pressure, $T$ is the gas temperature, $c_{m}$ is the mean piston speed, $c_{u}$ is the instantaneous swirl speed, $V_{d}$ is the displaced volume, $p_{I V C}, T_{I V C}$ and 
$V_{I V C}$ are the pressure, temperature and volume at IVC respectively, $p_{0}$ is the motoring pressure assuming a polytropic evolution, $C=0.012$ is a constant value and $C_{w 1}, C_{w 2}$ and $C_{2}$ are model fitting constants, whose values are presented in Table 5.

The tuning method is based on the application of the first law of thermodynamics to obtain the RoHR, which should be zero in motoring test. A multi-variable linear regression is used to find the parameters optimal values with the criteria of RoHR uncertainty minimization (this procedure is comprehensively explained in [32]).

The characterization was applied in a speed swept between 1500 and $2400 \mathrm{rpm}$. The reference and adjusted values of each parameter are presented in Table 5 and the instantaneous evolution of RoHR at each motoring test is presented in Figure 2, where it is possible to see how the uncertainty was reduced almost to zero.

\subsection{Heat transfer adjustment in combustion operation}

The accurate determination of the HT is necessary for a proper GEB and combustion analysis. By observing Equation (14), it is possible to conclude that the principal uncertainty that affects the RoHR is the HT, considering that the experimental equipment have been properly calibrated and some other uncertainties were adjusted as described in previous section. Considering that the thermodynamic conditions between motoring and combustion test can significantly vary [7], it is interesting to perform a refinement of the HT model constant $C_{2}$ in Equation (15) to ensure good accuracy. The criteria followed consist on minimizing the Mean Squared Error $\left(M S E_{A C E}\right)$ between the Apparent Combustion Efficiency (ACE) and the combustion efficiency $\left(\eta_{c o m b}\right)$ in the whole matrix of combustion test, being ACE defined as:

$$
\mathrm{ACE}=\frac{H R_{\max }}{\dot{m}_{f} H_{v}}
$$

where $H R_{\max }$ is the maximum heat released, obtained through integration of Equation (14).

The resulting value of $C_{2}$ is included in Table 5 . Note that this adjustment does not imply any incoherence with the motoring results, since $C_{2}$ only affects the combustion operation. To evaluate the performance of the adjustment, in Figure 3 the ACE calculated with the adjusted $C_{2}$ value and the $\eta_{\text {comb }}$ for the part load reference points are presented. It is possible to see that the uncertainty in all the operating points is low, having mean values about $\pm 2 \%_{f} \dot{m}_{f}$, thus the adjustment has a good performance at these conditions for this kind of thermodynamic models [32].

\subsection{Global energy balance tool validation}

Once the tool is calibrated, its performance to calculate the GEB was checked by means of the total experimental $\left(\dot{Q}_{t o t, e x p}\right)$ and modelled $\left(\dot{Q}_{t o t, m o d}\right)$ HT terms, which are defined in Equations (17) and (18): 


$$
\begin{gathered}
\dot{Q}_{t o t, m o d}=\dot{Q}_{\text {cham }, \text { cool }}+\dot{Q}_{\text {cham }, o i l}+\dot{Q}_{\text {ports }} \\
\dot{Q}_{\text {tot }, \text { xxp }}=\left(\dot{Q}_{c o o l}-\dot{Q}_{E G R}\right)+\dot{Q}_{o i l}-N_{f r}+\dot{Q}_{e x t}
\end{gathered}
$$

The results are presented in Figure 4, where it is possible to see the good agreement between the experimental and modelled terms. The uncertainty for all operating points is low, ranging between $\pm 3 \% \dot{m}_{f} H_{v}$.

\section{Results and discussion}

With the objective of analyzing the effect of dual-fuel operation, the GEB is carried out at different parametric studies:

- Diesel/gasoline mixture fraction evaluated in A1 to A3 operating conditions. The aim is to determine the effect of the low reactivity fuel on the engine thermal performance.

- Diesel SoI swept at 2 fixed gasoline rates (i.e. 70 and 90\%XPFI) without EGR at A1 part load point.

- Diesel SoI swept at $80 \% X P F I$ with and without EGR at A1 part load point.

The objective of these studies was to gradually change the combustion from diffusion controlled to reactivity controlled. From these studies, the potential of the RCCI combustion in comparison with the CDC will be assessed in terms of engine indicated and thermal efficiencies and energy balance.

To explain the thermal and combustion characteristics of each study, the temporal evolution of the RoHR and the bulk gas temperature $\left(T_{g}\right)$ are presented for some representative operating points. Moreover, to improve the analysis, the crank angle at 10 and 90\% mass fraction burned (CA10 and CA90) are also included as indicators of the start and end of combustion respectively. The combustion duration is assumed to be AC90-AC10.

\subsection{Effect of increasing the gasoline fraction in the blend}

For the initial investigations, when the gasoline mass fraction (\%XPFI) was swept, the DI-timing and the EGR rate were varied to maintain a constant CA50 and $N O_{x}$ levels. The total fuel injected was slightly adjusted to maintain the same brake power output. The gasoline mass fraction was continuously increased until the combustion either became unstable or until the premixed fuel ignited before the Diesel fuel injection. the rest of operating settings were kept constant independently of the gasoline mass fraction.

Figure 5 shows the temporal evolution of the RoHR and $T_{g}$ for the cases of CDC, 20, 50 and $80 \% X P F I$ at the A1 partial load point. CA10 and CA90 for the different \%XPFI are shown at the right of Figure 5. As can be seen, in the 
case of CDC, although there is a peak in the RoHR few degrees after TDC, the combustion is longer than in dual-fuel operation. In fact, when increasing the \%XPFI, the RoHR peak becomes lower and the combustion shorter. This can by explained by the shorter Diesel injection and hence the shorter diffusion controlled combustion, which leads to a delayed end of combustion, as can be observed from CA90. The shorter Diesel injection and the low global reactivity in the chamber lead to a larger combustion delay, therefore the Diesel SoI has to be advanced in the compression stroke to keep the combustion phasing. When increasing the gasoline fraction, specially at high gasoline values, the combustion starts earlier in the compression stroke thus producing an increase in temperature and pressure (see the bottom Figure 5), which allows burning most of the remaining fuel at low burning rates due to the reduced reactivity of the mixture.

Before starting the analysis of the GEB, it is interesting to highlight that $\eta_{\text {comb }}$ is close to $100 \%_{f} H_{v}$ in CDC as shown in Figure 3, therefore $\eta_{i}$ has almost the same value as $\eta_{t h}$ in this case. It is convenient to start the analysis of the GEB with the incomplete combustion losses, since it can help to explain some behaviours observed in the other energy terms. $\Theta_{i c}$ for different Diesel/gasoline compositions mixtures at each operating points is presented in Figure 6. For all operating conditions $\Theta_{i c}$ is higher than the Diesel reference, reaching values up to $7.5 \% \dot{m}_{f} H_{v}$ at high gasoline fractions. The trend to increase $\Theta_{i c}$ as $\% X P F I$ becomes higher changes at a determined mixture composition that depends on the point. The decrease of the $C O$ emissions at high \%XPFI can be justified through the increase in the fuel/air ratio of the homogeneous charge when increasing the gasoline injection. At these conditions, the lower air mass fractions leads to higher combustion products temperature, reaching the limit for the $\mathrm{CO}$ oxidation into $\mathrm{CO}_{2}$. The $\% X P F I$ at which the $\Theta_{i c}$ peek is reached changes at different operation points due to the different in-cylinder conditions

As observed in Figure 7, the heat rejection to chamber walls $\left(\Theta_{\text {cham }}\right)$ for low gasoline fraction has a similar level as $\mathrm{CDC}$; however, it tends to diminish when increasing the gasoline fractions due to the change of the mean gas temperature showing in Figure 5. $\Theta_{\text {cham }}^{\text {th }}$ has slightly higher values than $\Theta_{\text {cham }}$ (due to the changes in $\Theta_{i c}$ ), being up to $1 \% \dot{m}_{f} H_{v}$ higher than the $\mathrm{CDC}$ at points $\mathrm{A} 1$ and $\mathrm{A} 2$.

As shown in Figure 8, the trend of $\Theta_{\text {ports }}$ is similar as $\Theta_{\text {cham }}$ when increasing the gasoline fraction: at low $\% X P F I, \Theta_{\text {ports }}$ is similar as CDC; however, the higher the \%XPFI the lower the $\Theta_{\text {ports }}$ becomes, reaching values about $1.5 \% \dot{m}_{f} H_{v}$ lower than CDC. This is explained by the earlier CA90, which leads to lower mean gas temperature at the end of combustion (see Figure 5 bottom), and hence to lower temperature drop between the gas and the ports walls. The trend observed for $\Theta_{\text {ports }}^{\text {th }}$ is the same as $\Theta_{\text {ports }}$, decreasing their differences as the \%XPFI diminishes; however, the maximum effect of the incomplete combustion on this term hardly reaches $0.5 \% \dot{m}_{f} H_{v}$.

The relative weight of the net flow of sensible enthalpy $\left(\Theta_{g}\right)$ is presented in Figure 9. In points A1 and A3, $\Theta_{g}$ 
has similar values as the $\mathrm{CDC}$ with variations about $\pm 0.5 \% \dot{m}_{f} H_{v}$. For point $\mathrm{A} 2$, lower $\Theta_{g}$ compared with $\mathrm{CDC}$ is observed, reaching values up to $-2 \% \dot{m}_{f} H_{v}$. A general decreasing trend when increasing the $\% X P F I$ is observed in all operating points, which is explained by the lower mean gas temperature at the end of combustion (and hence lower exhaust temperature), as shown in Figure 5 top. In the case of $\Theta_{g}^{\text {th }}$, the values are shifted towards higher exhaust losses due to the effect of the combustion incompleteness, thus $\Theta_{g}^{t h}$ is about $0.5 \% \dot{m}_{f} H_{v}$ higher than CDC at points A1 and $\mathrm{A} 3$, and have similar values at point $\mathrm{A} 2$.

Finally, the engine indicated and thermal efficiencies are evaluated in Figure 10, where it is possible to see that $\eta_{i}$ is always lower than the Diesel reference, being this mainly explained by the lower combustion efficiency (higher $\Theta_{i c}$ ). Due to the important incomplete combustion losses in dual-fuel operation, the total amount of fuel injected has to be slightly increased to keep the same imep, thus reducing $\eta_{i}$. However, $\eta_{t h}$ has similar values as CDC at low \%XPFI and a clear trend to increase when higher gasoline fractions are used. Therefore, at the conditions of this study (same CA50 and $\tau_{E G R}$ ), it can be stated that the thermal conversion efficiency at high \%XPFI is better than that of CDC. This improvement can be mainly explained by the changes in the combustion process, and hence, on the heat release rate (earlier CA90, see Figure 5).

\subsection{Effect of Diesel injection timing at different $\% X P F I$}

Once the effect of dual-fuel operation on the GEB using different gasoline ratios has been analysed, the effect of advancing the DI injection event, gradually changing from a diffusion controlled combustion to RCCI operation, is studied. This study is focused on the A1 operating point, where a Diesel SoI swept for the cases of 70 and $90 \% X P F I$ without EGR is evaluated.

The RoHR for the two extreme SoI and an intermediate value of the SoI swept at 90\%XPFI is presented in the bottom of Figure 11. As can be seen in SoI $-1.7^{\circ}$, delaying the Diesel injection in the compression stroke results in a higher RoHR peak since the thermodynamic conditions in the chamber (i.e. high temperature and pressure) are favourable to start the combustion process after a delay of few crank angle degrees. In this delayed conditions, the first combustion event increases the pressure and temperature in the chamber and is followed by a slower combustion of the premixed mixture. Advancing the SoI (SoI $-21.7^{\circ}$ case) results in longer combustion delay, which leads to higher mixture of the Diesel fuel with the charge, and hence, a slightly shorter global combustion process as can be seen in Figure 11. At these conditions the peak of the RoHR is lower than in SoI $-1.7^{\circ}$ case. Advancing the SoI further than $-22^{\circ}$ (SoI $-39.2^{\circ}$ case) leads to a combustion process close to RCCI mode; this occurs because the Diesel is injected in a low temperature and pressure environment, being insufficient to start the combustion during the injection, thus, leading to higher stratification of the Diesel fuel/air ratio, and hence to lower reactivity of the charge near the Diesel spray in comparison with the delayed injection cases. As expected, the important changes in the shape of the RoHR affects the rest of the analysed terms. 
Regarding the GEB, the following comments can be done:

- The incomplete combustion losses $\left(\Theta_{i c}\right)$ depend mainly on the amount of gasoline injected, thus, the higher the $\% X P F I$ leads to higher $\dot{H}_{i c}$ as shown in Figure 12. Delaying the SoI leads to an increase of $\Theta_{i c}$, more noticeable at $70 \% X P F I$. It is interesting to highlight that advancing the SoI at low gasoline rate leads to $\Theta_{i c}$ similar as CDC.

- As shown in Figure 13, $\eta_{i}$ is lower than the CDC, which is explained by the incomplete combustion losses. This is evident by observing the thermal efficiency, where increasing \%XPFI leads to higher $\eta_{t h}$. The variation of $\eta_{i}$ with the SoI is low, except at very delayed SoI as a result of the large changes in the RoHR (later and longer combustion, see Figure 11). This trend is also observed in $\eta_{t h}$ at $90 \% X P F I$ because the increase in $\Theta_{i c}$ by delaying the SoI does not compensate the reduction of $\eta_{i}$, on the contrary, this trend is not observed in the case of $70 \%$ XPFI because the increase of $\Theta_{i c}$ compensates the reduction of $\eta_{i}$.

The higher $\eta_{t h}$ at $90 \% X P F I$ is explained by the better shape of the RoHR as shown in Figure 14. It can be seen that the RoHR at $90 \% X P F I$ is more centred around TDC than $70 \% X P F I$ at the SoI compared $\left(-21^{\circ}\right.$ aTDC), moreover, this general trend with \%XPFI can be also seen in Figure 10 (despite it is not the same study). Delaying the SoI at 70\%XPFI (and centring the combustion) does not lead to increase in $\eta_{t h}$ as consequence of the high increase in $\Theta_{i c}$.

- The level difference between $\Theta_{\text {cham }}$ and $\Theta_{\text {cham }}^{\text {th }}$ is explained by $\Theta_{i c}$, similarly as for the indicated efficiency. The HT has a clear trend to increase at intermediate SoI, which can be justified by the temperature difference observed in Figure 11, where the higher temperature is observed at the intermediate SoI (-21.7 ${ }^{\circ}$ aTDC). As can be seen in Figure 13, $\Theta_{\text {cham }}$ reduction due to delaying or advancing the SoI with respect to the intermediate one does not lead to higher $\eta_{i}$ as a consequence of the changes in the RoHR (see Figure 11).

As shown in Figure 14, the higher the \%XPFI the lower the temperature. This is explained by the delayed combustion when increase the \%XPFI, which also leads to lower HT. It can be concluded that this lower $\Theta_{\text {cham }}^{\text {th }}$ along with the better combustion phasing at $90 \% X P F I$ leads to higher $\eta_{t h}$ than CDC.

- In the case of the HT losses to the ports $\left(\Theta_{\text {ports }}\right.$ and $\left.\Theta_{\text {ports }}^{\text {th }}\right)$, they are about $2 \% \dot{m}_{f} H_{v}$ lower than CDC, which is explained by the lower exhaust temperature of dual-fuel (between $280-290^{\circ} \mathrm{C}$ ) in comparison with CDC $\left(318^{\circ} \mathrm{C}\right)$. There is a slight trend to reduce $\Theta_{\text {ports }}$ and $\Theta_{\text {ports }}^{\text {th }}$ when increasing the $\%$ XPFI.

- The trends observed in $\Theta_{g}$ are explained similarly as for $\Theta_{\text {ports. }}$. The level difference between $\Theta_{g}$ and $\Theta_{g}^{t h}$ is higher than that observed for the ports, due to the higher proportional effect of the incomplete combustion. 
At high \%XPFI, the thermal efficiency of dual-fuel operation is better than that of CDC, but the combustion efficiency has to be enhanced to improve the indicated efficiency. In the following study, the effect of EGR strategy will be analysed as an alternative to improve the engine efficiency and the global thermal process.

\subsection{Effect of the EGR rate}

To perform a fair comparison between dual-fuel and CDC, the final step is to evaluate the effect of the EGR strategy. To do that, a swept of SoI for 0 and $30 \%$ of EGR is analysed, using a fixed amount of gasoline of $80 \% X P F I$ at the A1 part load operating point.

In Figure 15, it is possible to see the effect of increase the EGR rate on the RoHR at a fixed SoI of $-21.2^{\circ}$. As shown, the increase of EGR leads to higher combustion delay and slower combustion development, which is explained by the lower reactivity of the charge. In dual-fuel operation, when $\tau_{E G R}$ increases, the combustion process ends later in the expansion stroke, which leads to higher exhaust temperature as shown in Table 6. It is interesting to highlight that $\mathrm{CDC}$ has a significantly higher exhaust temperature $\left(318^{\circ} \mathrm{C}\right)$ than dual-fuel, which is explained as part of the combustion occurs during the expansion stroke (AC90 in CDC lies about $27^{\circ}$ aTDC).

With respect to the GEB, the following observations can be made:

- As shown in Figure 16, $\Theta_{i c}$ is slightly lower when using EGR. This trend is due to the higher mean gas temperature during compression and most of the expansion, as shown Figure 15. It is interesting to highlight that the variations of $\Theta_{i c}$ due to using EGR are lower than those by changing \%XPFI (see Figure 12).

- The EGR does not affect $\eta_{t h}$ as shown in Figure 17. However, $\eta_{i}$ shows a slight variation as consequence of $\Theta_{i c}$ effect (i.e. higher amount of fuel to reach the same imep). With a proper SoI and $\tau_{E G R}$, about $1 \% \dot{m}_{f} H_{v}$ higher $\eta_{i}$ can be achieved in comparison with CDC.

- The effect on $\Theta_{\text {cham }}$ and $\Theta_{\text {cham }}^{t h}$ with the SoI is the same as that commented in section 5.2, reaching the maximum value at intermediate SoI and being higher than CDC. As can be seen in Figure 15, using EGR increases the mean gas temperature, thus, $\Theta_{\text {cham }}$ also increases. In the case of $\Theta_{\text {cham }}^{\text {th }}$, similar values are observed with and without EGR, as consequence of $\Theta_{i c}$.

- Using EGR leads to higher exhaust temperature (see Table 6) due to the higher mean gas temperature and the delayed combustion, as shown in Figure 15, thus leading to the higher $\Theta_{\text {ports }}$ and $\Theta_{\text {ports }}^{\text {th }}$ observed in Figure 17. Note that even with the increase of the exhaust temperature when using EGR, this is still lower than that of $\mathrm{CDC}$, thus, the HT to ports is lower for dual-fuel operation. 
- As the objective of this study is to analyse the effect of the EGR, the terms $\Theta_{g}$ and $\Theta_{E G R}$ are analysed together in order to get comparable quantities. The addition of these terms corresponds to the net sensible enthalpy calculated between intake and exhaust ports. Using EGR leads to increments of the intake temperature up to $10^{\circ} \mathrm{C}$, while in the exhaust about $15-20^{\circ} \mathrm{C}$, thus increasing the intake-exhaust temperature difference, and hence, the net sensible enthalpy. Despite the increase of $\Theta_{g}+\Theta_{E G R}, \Theta_{g}^{t h}+\Theta_{E G R}^{t h}$ reaches values similar as CDC (with and without EGR).

From the previous analysis, it is possible to conclude that the thermal efficiency of dual-fuel operation is better than CDC (higher $\eta_{t h}$ up to $4 \% \dot{m}_{f} H_{v}$ ) in spite of the higher $\Theta_{\text {cham }}^{\text {th }}$. With the proper SoI and $\tau_{E G R}$, higher $\eta_{i}$ about $1 \% \dot{m}_{f} H_{v}$ can also be attained. However, there is still room to improve the engine efficiency by reducing the incomplete combustion losses.

\section{Summary and Conclusions}

In this work, the combustion and thermal behaviour of a single-cylinder research engine operating with dual-fuel has been evaluated. This study combines experimental and modelling tools to analyse the efficiency as well as the power losses of the engine by performing and analysing the GEB.

As a first step, the calibration of the tool have been presented, starting from the engine characterization based on motoring tests and a multiple linear regression methodology. Then, the adjustment of the HT model using combustion tests to reduce the ACE and the $\eta_{c o m b}$ difference is performed. From these results, a maximum uncertainty between $\pm 2 \% \dot{m}_{f} H_{v}$ was achieved.

To validate the GEB tool, the experimental and modelled total HT were compared. A general good agreement was observed between them, having a main uncertainty about $3 \% \dot{m}_{f} H_{v}$ in all operating conditions. Therefore, it is concluded that the model is reliable enough to determine the energy terms defined in this work.

The study is finally centred in analysing the effect of varying the \%XPFI, the SoI and the EGR, thus approaching from a CDC to a RCCI combustion. The main trends observed in the stated studies are listed below:

- At higher \%XPFI, $\eta_{t} h$ is better than the CDC, mainly explained by the changes in the RoHR; however, $\eta_{i}$ has not reached the CDC values. This is explained by the lower combustion efficiency at these conditions, and hence the higher $\Theta_{i c}$ losses.

- The highest $\eta_{i}$ and $\eta_{t} h$ are reached at SoI between -20 and $-25^{\circ}$ aTDC. In the case of $\eta_{t h}$, higher values than those of CDC have been observed, which indicates a better thermal process of the dual-fuel mode; however, the 
weight of the HT and the exhausts losses were also increased to levels similar or higher than CDC.

- The use of EGR at $80 \% X P F I$ leads to further improvements of the combustion process and combustion efficiency, which results in about $1 \% \dot{m}_{f} H_{v}$ higher $\eta_{i}$ at intermediate SoI in comparison with CDC. The thermal behaviour of the engine is also enhanced, reaching up to $4 \% \dot{m}_{f} H_{v}$ higher $\eta_{t h}$ than CDC.

From the results reported in this work, it can be concluded that both, the indicated and thermal efficiencies of the dual-fuel concept are better than the CDC when using optimal SoI and EGR rate. The potential of the RCCI mode is evidenced by the higher thermal efficiency, and further investigations to improve the combustion efficiency are worth.

\section{Acknowledgments}

The support of the Spanish Ministry of Economy and Competitiveness (TRA2013-41348-R) is greatly acknowledged. 


\section{References}

[1] Regulation (EU) No 333/2014 of the European Parliament and of the Council of 11 March 2014 amending Regulation (EC) No $443 / 2009$ to define the modalities for reaching the 2020 target to reduce CO2 emissions from new passenger cars, Official Journal of the European Union L103 Vol 57 (2014) 15-21.

[2] C. Guardiola, J. López, J. Martín, D. García-Sarmiento, Semiempirical in-cylinder pressure based model for NOX prediction oriented to control applications, Applied Thermal Engineering 31 (12) (2011) 3275-3286. doi:10.1016/j.applthermaleng.2011.05.048.

[3] B. Mohan, W. Yang, S. K. Chou, Fuel injection strategies for performance improvement and emissions reduction in compression ignition engines-A review, Renewable and Sustainable Energy Reviews 28 (2013) 664-676. doi:10.1016/j.rser.2013.08.051.

[4] S. Jaichandar, K. Annamalai, Combined impact of injection pressure and combustion chamber geometry on the performance of a biodiesel fueled diesel engine, Energy 55 (2013) 330-339. doi:10.1016/j.energy.2013.04.019.

[5] M. Canakci, Combustion characteristics of a DI-HCCI gasoline engine running at different boost pressures, Fuel 96 (2012) 546-555 doi:10.1016/j.fuel.2012.01.042.

[6] F. Perini, P. C. Miles, R. D. Reitz, A comprehensive modeling study of in-cylinder fluid flows in a high-swirl, light-duty optical diesel engine, Computers \& Fluids 105 (2014) 113-124. doi:10.1016/j.compfluid.2014.09.011.

[7] P. Olmeda, J. Martín, R. Novella, R. Carreño, An adapted heat transfer model for engines with tumble motion, Applied Energy 158 (2015) 190-202. doi:10.1016/j.apenergy.2015.08.051.

[8] R. Verschaeren, W. Schaepdryver, T. Serruys, M. Bastiaen, L. Vervaeke, S. Verhelst, Experimental study of NOx reduction on a medium speed heavy duty diesel engine by the application of EGR (exhaust gas recirculation) and Miller timing, Energy 76 (2014) 614-621. doi:10.1016/j.energy.2014.08.059.

[9] E. Sher, T. Bar-Kohany, Optimization of variable valve timing for maximizing performance of an unthrottled SI engine-a theoretical study, Energy 27 (2002) 757-775. doi:10.1016/S0360-5442(02)00022-1.

[10] G. Karavalakis, D. Short, D. Vu, R. L. Russell, A. Asa-Awuku, H. Jung, K. C. Johnson, T. D. Durbin, The impact of ethanol and iso-butanol blends on gaseous and particulate emissions from two passenger cars equipped with spray-guided and wall-guided direct injection SI (spark ignition) engines, Energy 82 (2015) 168-179. doi:10.1016/j.energy.2015.01.023.

[11] V. Bermúdez, J. M. Luján, P. Piqueras, D. Campos, Pollutants emission and particle behavior in a pre-turbo aftertreatment light-duty diesel engine, Energy 66 (2014) 509-522. doi:10.1016/j.energy.2014.02.004.

[12] H. Bendu, S. Murugan, Homogeneous charge compression ignition (HCCI) combustion: Mixture preparation and control strategies in diesel engines, Renewable and Sustainable Energy Reviews 38 (2014) 732-746. doi:10.1016/j.rser.2014.07.019.

[13] A. C. Alkidas, Combustion advancements in gasoline engines, Energy Conversion and Management 48 (11) (2007) 2751-2761. doi:10.1016/j.enconman.2007.07.027.

[14] G. D. Neely, S. Sasaki, J. A. Leet, Experimental Investigation of PCCI-DI Combustion on Emissions in a Light-Duty Diesel Engine, SAE Techinical Paper 2004-01-0121doi:10.4271/2004-01-0121.

[15] Y. Ishibashi, M. Asai, Improving the Exhaust Emissions of Two-Stroke Engines by Applying the Activated Radical Combustion, SAE Techinical Paper 960742doi:10.4271/960742.

[16] S. Kimura, O. Aoki, Y. Kitahara, E. Aiyoshizawa, Ultra-Clean Combustion Technology Combining a Low-Temperature and Premixed Combustion Concept for Meeting Future Emission Standards, SAE Technical Paper 2001-01-0200doi:10.4271/2001-01-0200.

[17] J. M. Desantes, J. Benajes, A. García, J. Monsalve-Serrano, The role of the in-cylinder gas temperature and oxygen concentration over low load reactivity controlled compression ignition combustion efficiency, Energy 78 (2014) 854-868. doi:10.1016/j.energy.2014.10.080.

[18] J. Benajes, S. Molina, A. García, E. Belarte, M. Vanvolsem, An investigation on RCCI combustion in a heavy duty diesel engine using incylinder blending of diesel and gasoline fuels, Applied Thermal Engineering 63 (1) (2014) 66-76. doi:10.1016/j.applthermaleng.2013.10.052.

[19] J. Benajes, S. Molina, A. García, J. Monsalve-Serrano, Effects of direct injection timing and blending ratio on RCCI combustion with different low reactivity fuels, Energy Conversion and Management 99 (2015) 193-209. doi:10.1016/j.enconman.2015.04.046. 
[20] S. L. Kokjohn, R. M. Hanson, D. a. Splitter, R. D. Reitz, Fuel reactivity controlled compression ignition (RCCI): a pathway to controlled high-efficiency clean combustion, International Journal of Engine Research 12 (3) (2011) 209-226. doi:10.1177/1468087411401548.

[21] J. Benajes, J. V. Pastor, A. García, J. Monsalve-Serrano, The potential of RCCI concept to meet EURO VI NOx limitation and ultra-low soot emissions in a heavy-duty engine over the whole engine map, Fuel 159 (2015) 952-961. doi:10.1016/j.fuel.2015.07.064.

[22] J. Benajes, S. Molina, A. García, J. Monsalve-Serrano, Effects of low reactivity fuel characteristics and blending ratio on low load RCCI (reactivity controlled compression ignition) performance and emissions in a heavy-duty diesel engine, Energy 90 (2015) $1261-1271$. doi:10.1016/j.energy.2015.06.088.

[23] B. Heuser, F. Kremer, S. Pischinger, H. Rohs, B. Holderbaum, T. Körfer, An experimental investigation of dual-fuel combustion in a light duty Diesel engine by in-cylinder blending of ethanol and Diesel, SAE Techinical Paper 2015-01-1801.

[24] F. Payri, P. Olmeda, J. Martín, R. Carreño, Experimental analysis of the global energy balance in a DI diesel engine, Applied Thermal Engineering 89 (2015) 545-557. doi:10.1016/j.applthermaleng.2015.06.005.

[25] L. A. Smith, W. H. Preston, G. Dowd, O. Taylor, K. M. Wilkinson, Application of a First Law Heat Balance Method to a Turbocharged Automotive Diesel Engine, SAE Technical Paper 2009-01-2744doi:10.4271/2009-01-2744.

[26] O. Durgun, Z. Şahin, Theoretical investigation of heat balance in direct injection (DI) diesel engines for neat diesel fuel and gasoline fumigation, Energy Conversion and Management 50 (1) (2009) 43-51. doi:10.1016/j.enconman.2008.09.007.

[27] F. Caresana, M. Bilancia, C. Bartolini, Numerical method for assessing the potential of smart engine thermal management: Application to a medium-upper segment passenger car, Applied Thermal Engineering 31 (16) (2011) 3559-3568. doi:10.1016/j.applthermaleng.2011.07.017.

[28] D. Jung, J. Yong, H. Choi, H. Song, K. Min, Analysis of engine temperature and energy flow in diesel engine using engine thermal management, Journal of Mechanical Science and Technology 27 (2) (2013) 583-592. doi:10.1007/s12206-012-1235-4.

[29] F. Payri, P. Olmeda, J. Martin, R. Carreño, A New Tool to Perform Global Energy Balances in DI Diesel Engines, SAE Int. J. Enginesdoi:10.4271/2014-01-0665.

[30] M. Muether, M. Lamping, A. Kolbeck, R. Cracknell, Advanced Combustion for Low Emissions and High Efficiency Part 1: Impact of Engine Hardware on HCCI Combustion, SAE Techinical Paper 2008-01-2405doi:10.4271/2008-01-2405.

[31] F. Payri, J. Luján, J. Martín, A. Abbad, Digital signal processing of in-cylinder pressure for combustion diagnosis of internal combustion engines, Mechanical Systems and Signal Processing 24 (6) (2010) 1767-1784. doi:10.1016/j.ymssp.2009.12.011.

[32] J. Benajes, P. Olmeda, J. Martín, R. Carreño, A new methodology for uncertainties characterization in combustion diagnosis and thermodynamic modelling, Applied Thermal Engineering 71 (2014) 389-399. doi:10.1016/j.applthermaleng.2014.07.010.

[33] M. Muether, EinflÃEsse alternativer Kraftstoffe auf die dieselmotorische Verbrennung, Ph.D. thesis, RWTH Aachen University (2009).

[34] J. Heywood, Internal Combustion Engines Fundamentals, McGraw-Hill, New York, 1988.

[35] J. E. Dec, Y. Yang, Boosted HCCI for High Power without Engine Knock and with Ultra-Low NOx Emissions - using Conventional Gasoline, SAE International Jounral of Engines 3 (1) (2010) 750-767. doi:10.4271/2010-01-1086.

[36] J. Benajes, J. V. Pastor, A. García, J. Monsalve-Serrano, An experimental investigation on the influence of piston bowl geometry on RCCI performance and emissions in a heavy-duty engine, Energy Conversion and Management 103 (2015) 1019-1030. doi:10.1016/j.enconman.2015.07.047.

[37] F. Payri, P. Olmeda, J. Martín, A. García, A complete 0D thermodynamic predictive model for direct injection diesel engines, Applied Energy 88 (12) (2011) 4632-4641. doi:10.1016/j.apenergy.2011.06.005.

[38] F. Payri, J. Galindo, J. Martín, F. J. Arnau, A Simple Model for Predicting the Trapped Mass in a DI Diesel Engine, SAE Techinical Paper 2007-01-0494doi:10.4271/2007-01-0494.

[39] M. Lapuerta, O. Armas, J. Hernández, Diagnosis of DI Diesel combustion from in-cylinder pressure signal by estimation of mean thermodynamic properties of the gas, Applied Thermal Engineering 19 (5) (1999) 513-529. doi:10.1016/S1359-4311(98)00075-1.

[40] F. Payri, S. Molina, J. Martín, O. Armas, Influence of measurement errors and estimated parameters on combustion diagnosis, Applied Thermal Engineering 26 (2-3) (2006) 226-236. doi:10.1016/j.applthermaleng.2005.05.006.

[41] F. Payri, X. Margot, A. Gil, J. Martín, Computational Study of Heat Transfer to the Walls of a DI Diesel Engine, SAE Technical paper 
2005-01-0210doi:10.4271/2005-01-0210. 
Table 1: Engine technical data

\begin{tabular}{lc}
\hline Displacement & $390 \mathrm{~cm}^{3}$ \\
Bore & $75 \mathrm{~cm}$ \\
Stroke & $88.3 \mathrm{~cm}$ \\
Max. cylinder pressure & $190 \mathrm{bar}$ \\
DI system & Bosch piezo common rail \\
DI nozzle & 8 holes of $109 \mu \mathrm{m}$ and $153^{\circ}$ ea. \\
Max. injection pressure & $2200 \mathrm{bar}$ \\
PFI valve & E14, type E (2-spray) \\
Max. boosting pressure & 3.8 bar \\
\hline
\end{tabular}


Table 2: Emissions measurement equipment

\begin{tabular}{lll} 
Specie & Technique & Equipment \\
\hline $\mathrm{HC}$ & Flame ionization detector & Rosemount NGA 2000 \\
$\mathrm{O}_{2}$ & Paramagnetic oxygen analyser & Rosemount NGA 2000 \\
$\mathrm{CO}$ & Infrared gas analyser & Rosemount NGA 2000 \\
$\mathrm{CO}_{2}$ & Infrared gas analyser & Rosemount NGA 2000 \\
$\mathrm{NO}_{x}$ & Chemiluminescence analyser & Eco Physics 700 EL ht \\
$\mathrm{PM}$ & Filter paper method & AVL 415S \\
\hline
\end{tabular}


Table 3: Investigated fuel properties

\begin{tabular}{lll} 
& EN590 Diesel & EN228 gasoline \\
\hline $\mathrm{C}$ mass fraction [\%] & 84.47 & 82.97 \\
$\mathrm{H}$ mass fraction [\%] & 13.27 & 13.48 \\
$\mathrm{O}$ mass fraction [\%] & 2.26 & 3.56 \\
Density $\left(25^{\circ} \mathrm{C}\right)\left[\mathrm{kg} / \mathrm{m}^{3}\right]$ & 820 & 733.6 \\
Boiling temperature $\left[{ }^{\circ} \mathrm{C}\right]$ & $170-350$ & $28-188$ \\
Vapour pressure $\left(20^{\circ} \mathrm{C}\right)[\mathrm{kPa}]$ & $<0.1$ & 68.9 \\
Specific enthalpy of vaporization $[\mathrm{kJ} / \mathrm{kg}]$ & 358 & 420 \\
Stoichiometric air requirement & 14.8 & 14 \\
Lower heating value $[\mathrm{MJ} / \mathrm{kg}]$ & 42.8 & 42.1 \\
Research octane number $(\mathrm{RON})$ & - & 96.3 \\
Cetane number $(\mathrm{CN})$ & 53 & - \\
\hline
\end{tabular}


Table 4: Settings of the part load operating points

\begin{tabular}{ccccccccc} 
& $\begin{array}{c}\text { Speed } \\
{[\mathrm{rpm}]}\end{array}$ & $\begin{array}{c}\text { Load } \\
{[\mathrm{bar}]}\end{array}$ & $\begin{array}{c}p_{\text {rail }} \\
{[\mathrm{bar}]}\end{array}$ & $\begin{array}{c}\mathrm{CA} 50 \\
{\left[{ }^{\circ}\right]}\end{array}$ & $\begin{array}{c}T_{\text {int }} \\
{\left[{ }^{\circ} \mathrm{C}\right]}\end{array}$ & $\begin{array}{c}p_{\text {int }} \\
{[\mathrm{bar}]}\end{array}$ & $\begin{array}{c}p_{\text {exh }} \\
{[\mathrm{bar}]}\end{array}$ & $\begin{array}{c}N O_{x}(\mathrm{EU} 6) \\
{[\mathrm{g} / \mathrm{kWh}]}\end{array}$ \\
\hline $\mathrm{A} 1$ & 1500 & 6.8 & 900 & 5.8 & 30 & 1.50 & 1.6 & 0.2 \\
$\mathrm{~A} 2$ & 2280 & 9.4 & 1400 & 9.2 & 35 & 2.29 & 2.39 & 0.4 \\
$\mathrm{~A} 3$ & 2400 & 14.8 & 1800 & 10.8 & 46 & 2.6 & 2.8 & 0.6 \\
\hline
\end{tabular}


Table 5: Reference and adjustment parameters

\begin{tabular}{lcc} 
Parameter & Reference & Adjusted \\
\hline $\mathrm{CR}$ & $15: 1$ & $14.3: 1$ \\
$\Delta \alpha$ & 180.0 & 179.7 \\
$C_{w 1}$ & 1.95 & 1.13 \\
$C_{w 2}$ & 1.15 & 0.66 \\
$K_{d e f}$ & 2.2 & 3.53 \\
$C_{2}$ & 0.001 & 0.0017 \\
\hline
\end{tabular}


Table 6: Exhaust temperature at different $\tau_{E G R}$

\begin{tabular}{lccc} 
& $T_{\text {exh }}\left[{ }^{\circ} \mathrm{C}\right]$ & $T_{\text {exh }}\left[{ }^{\circ} \mathrm{C}\right]$ & $T_{\text {exh }}\left[{ }^{\circ} \mathrm{C}\right]$ \\
& $($ SoI -40) & $($ SoI -20) & $($ SoI -10) \\
\hline$\tau_{E G R}=0 \%$ & 270 & 279 & 280 \\
$\tau_{E G R}=15 \%$ & 278 & 284 & 288 \\
$\tau_{E G R}=30 \%$ & 290 & 292 & 294 \\
\hline
\end{tabular}




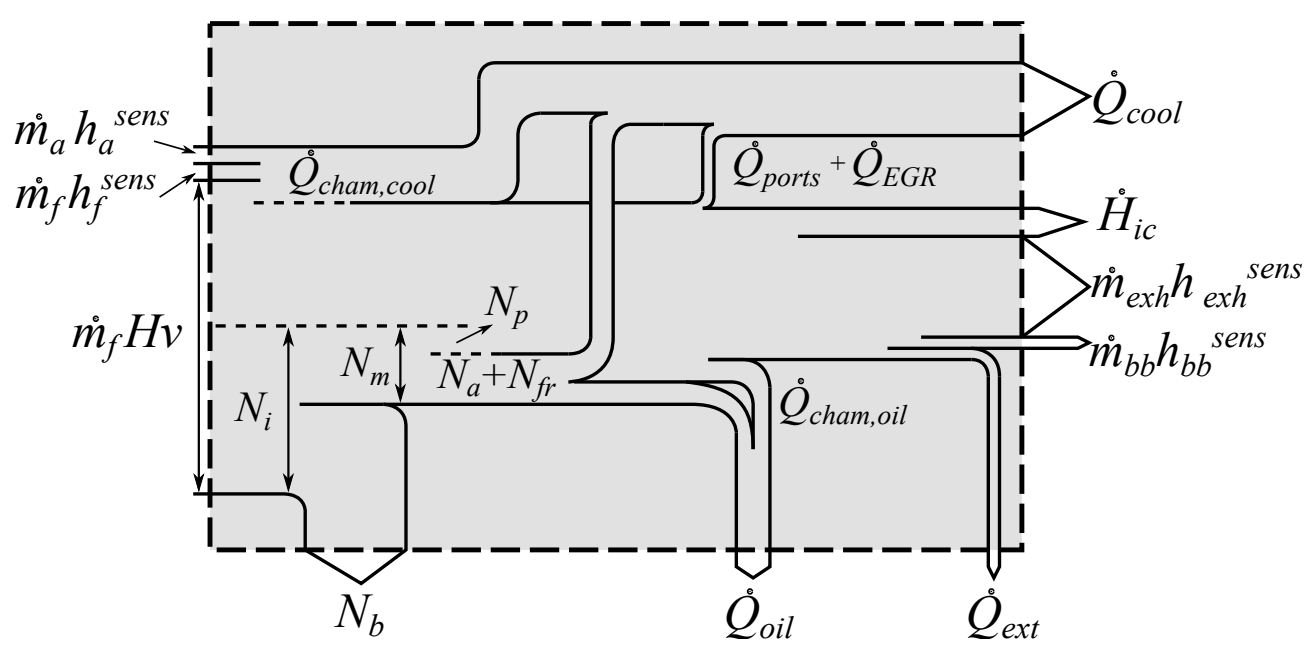

Figure 1: Single-cylinder engine flow path 


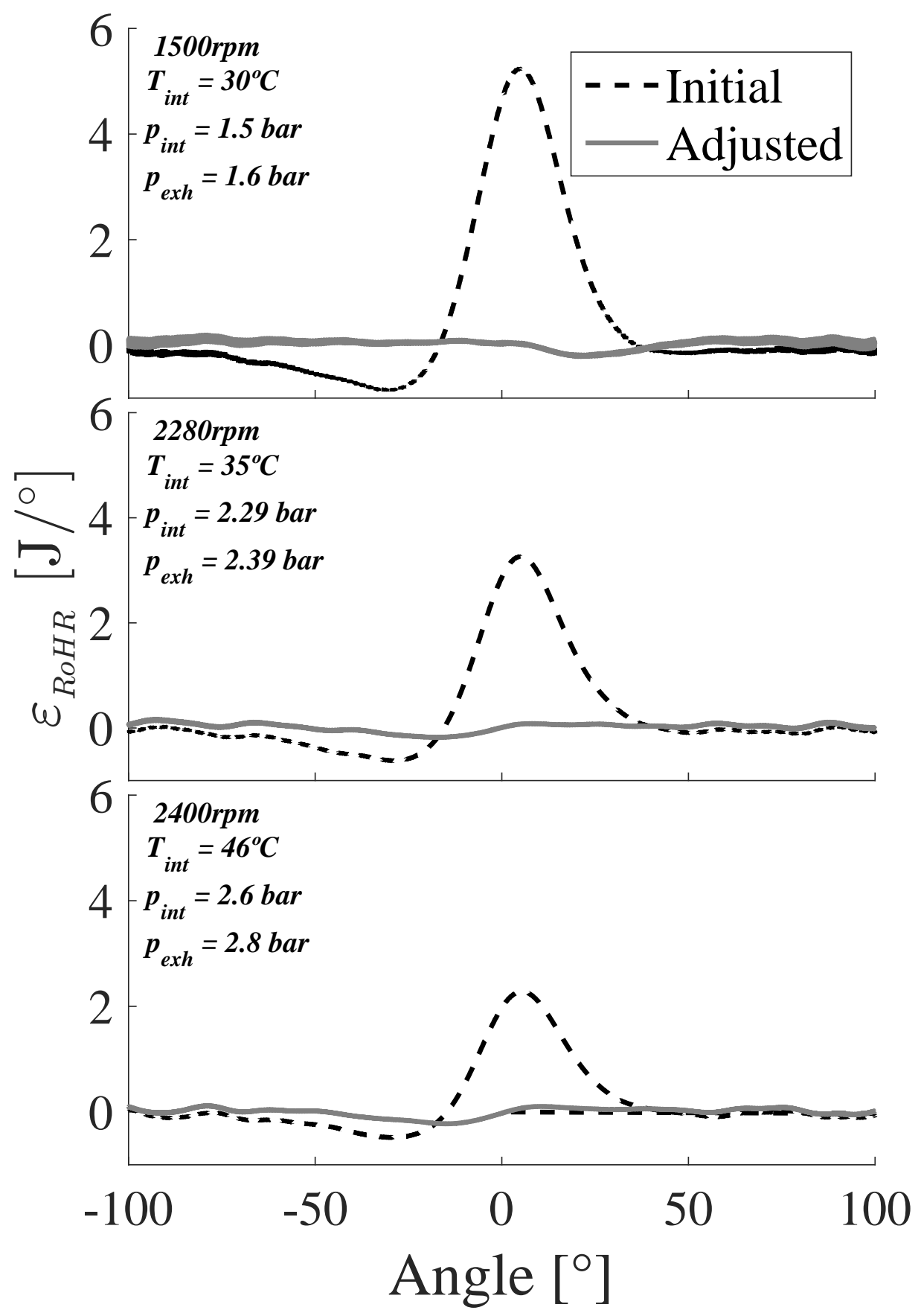

Figure 2: $\varepsilon_{R o H R}$ before and after adjustment in motoring conditons 


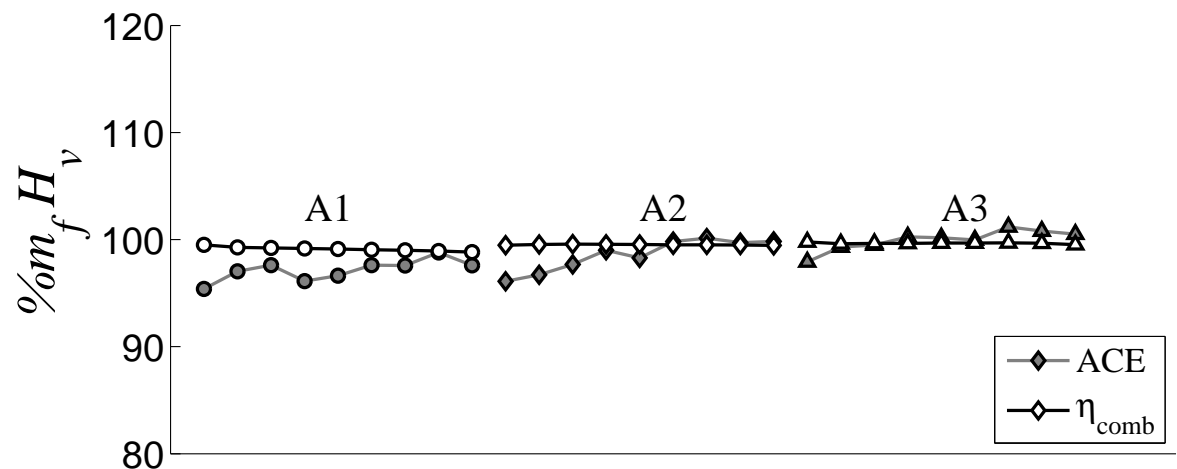

Figure 3: Comparison between ACE and $\eta_{c o m b}$ after adjustment 


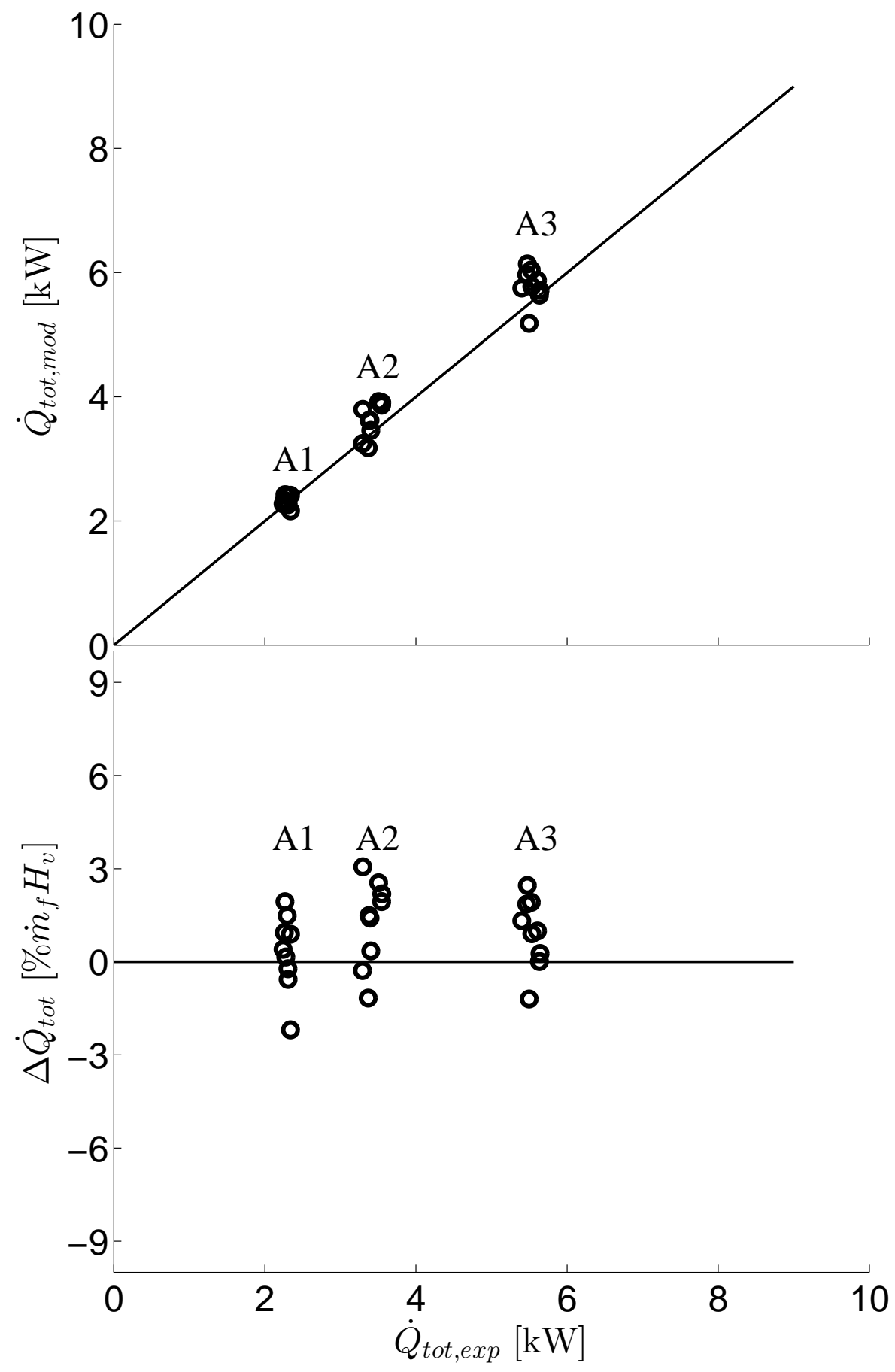

Figure 4: Experimental and modelled $\dot{Q}_{t o t}$ comparison 


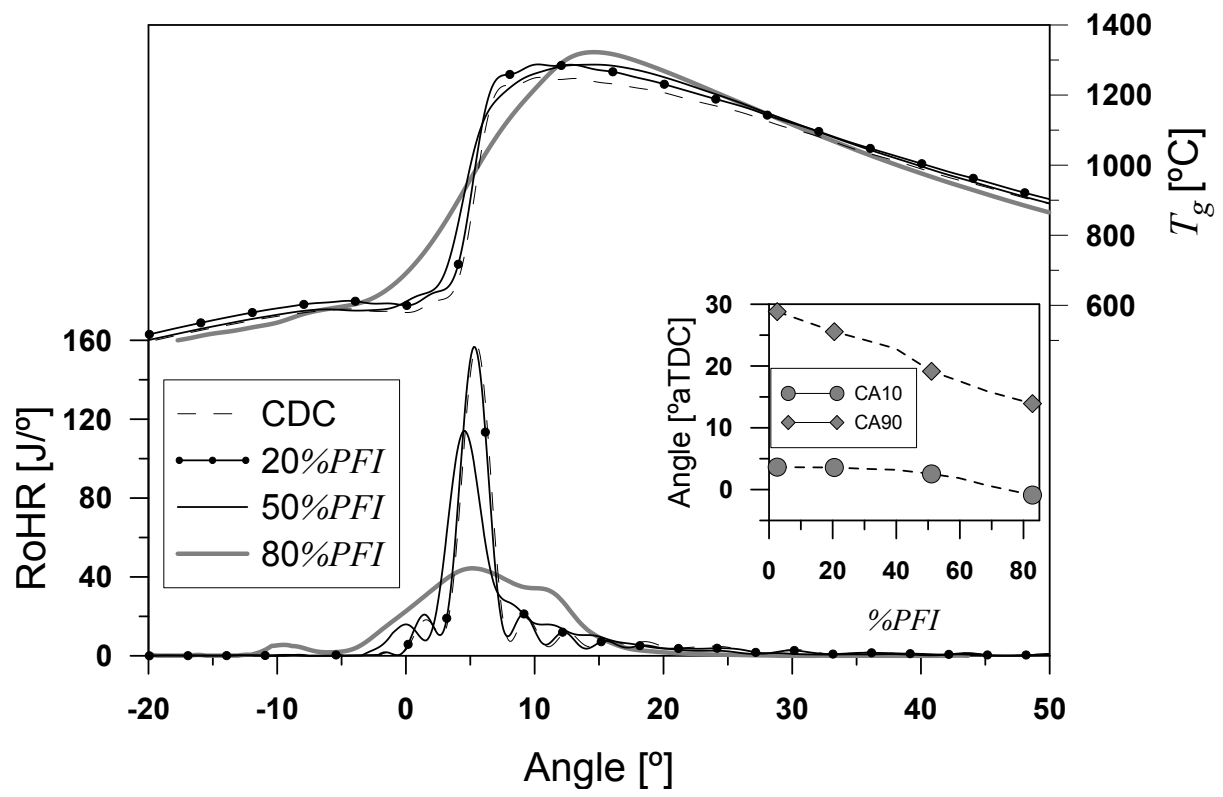

Figure 5: $T_{g}$ (top) and RoHR (bottom) for the A1 operating point 

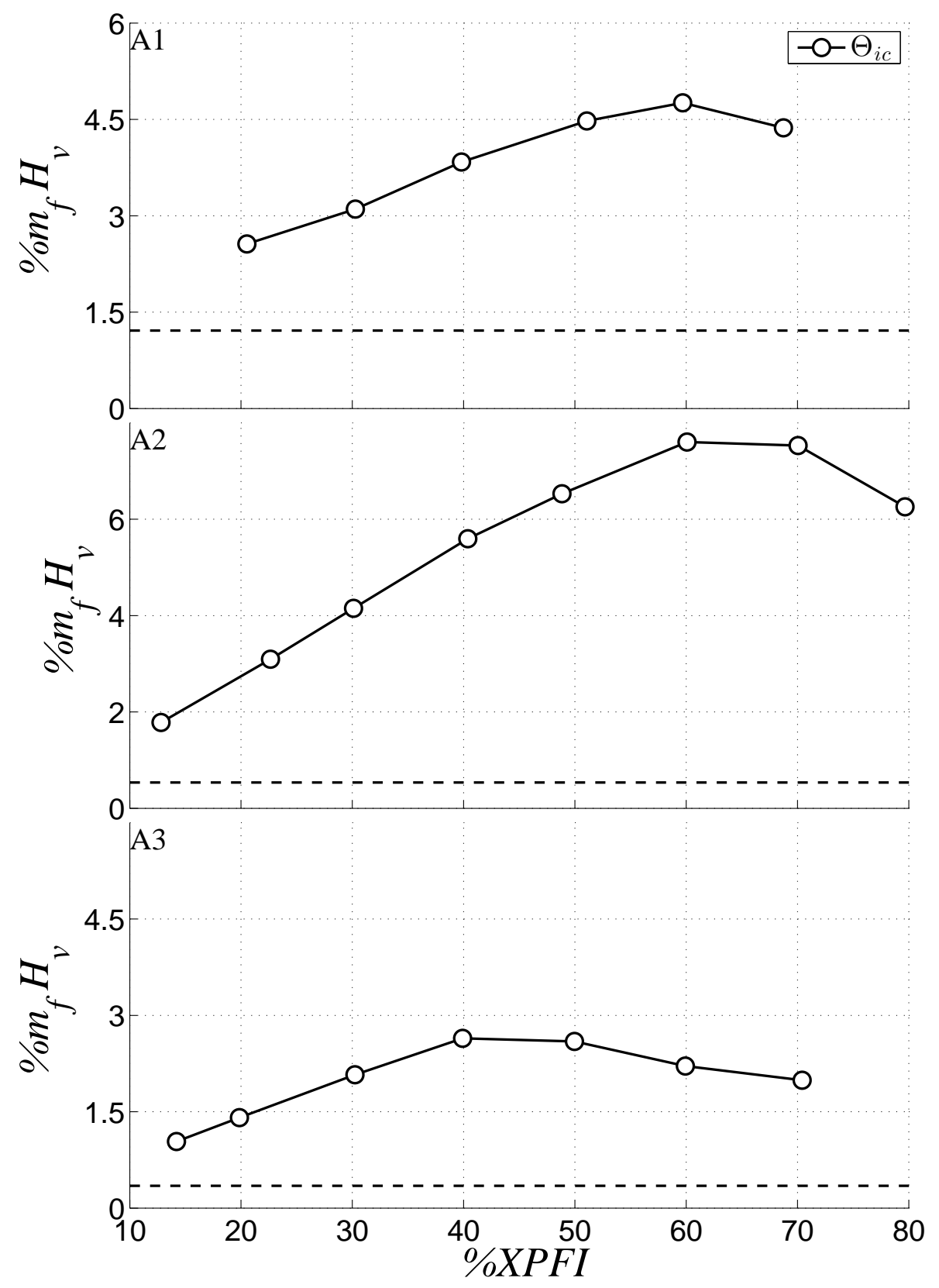

Figure 6: Incomplete combustion losses, CDC in dashed line 

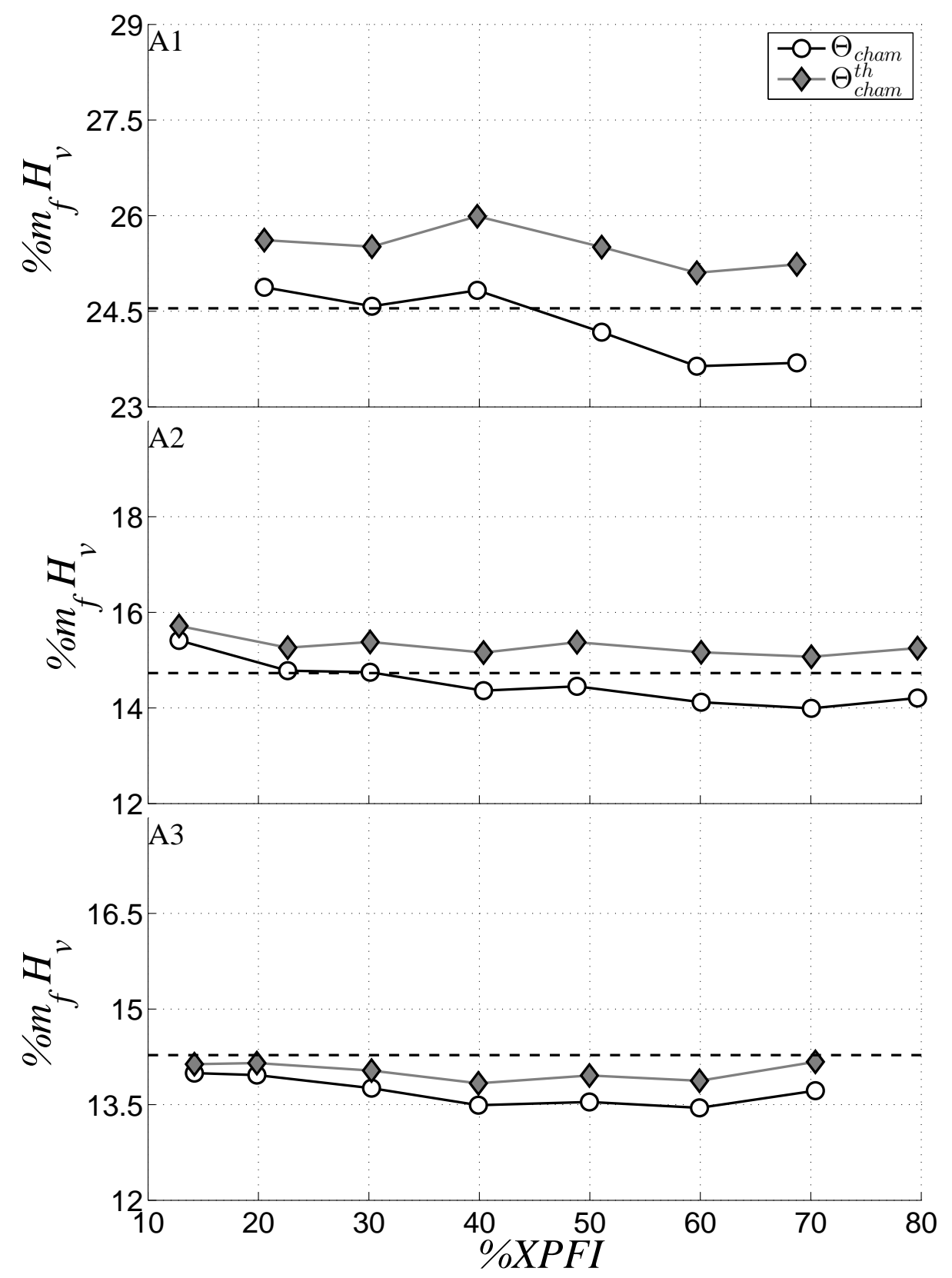

Figure 7: Heat transfer to chamber, $\mathrm{CDC}$ in dashed line 

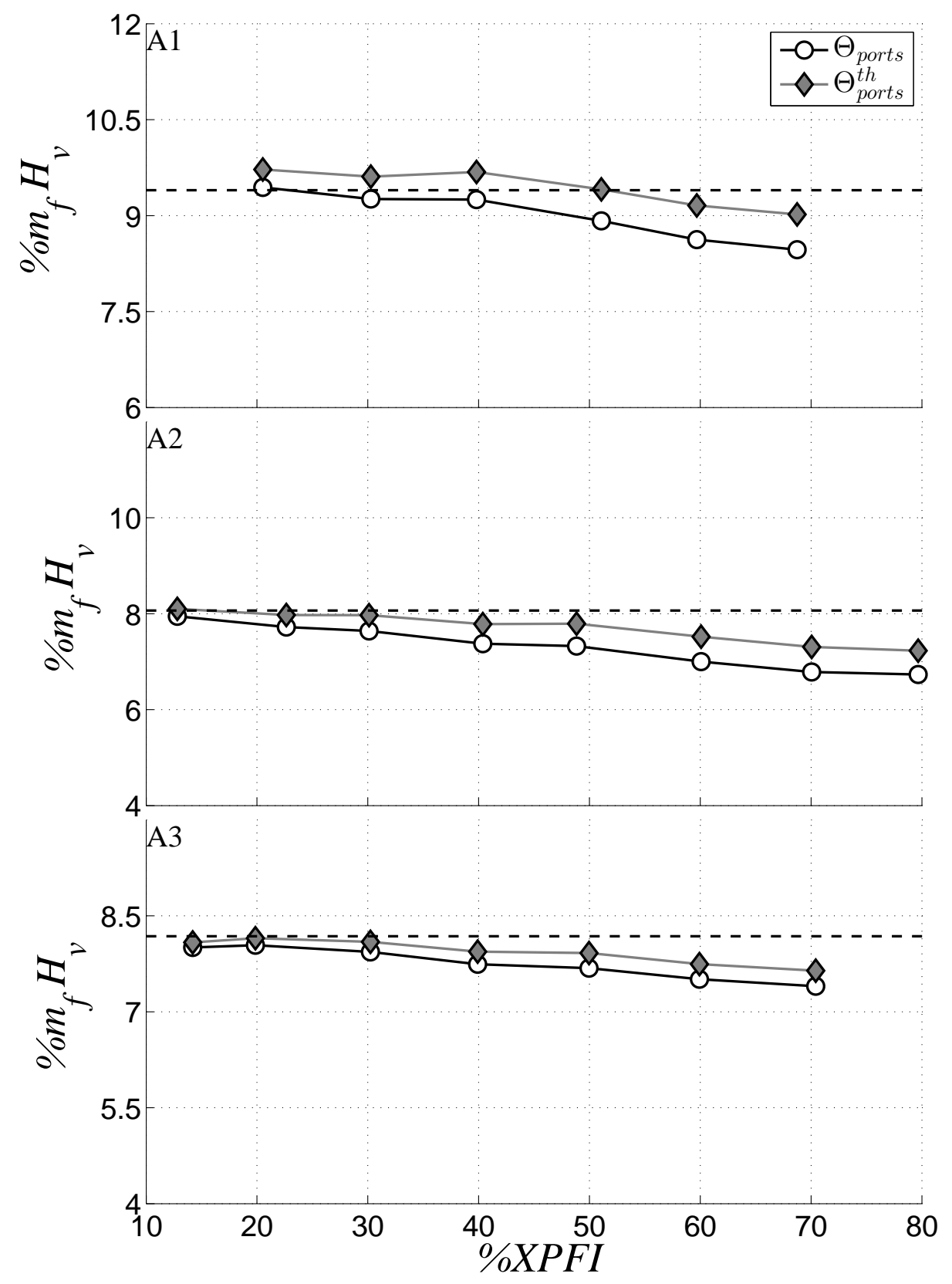

Figure 8: Heat transfer to ports, $\mathrm{CDC}$ in dashed line 

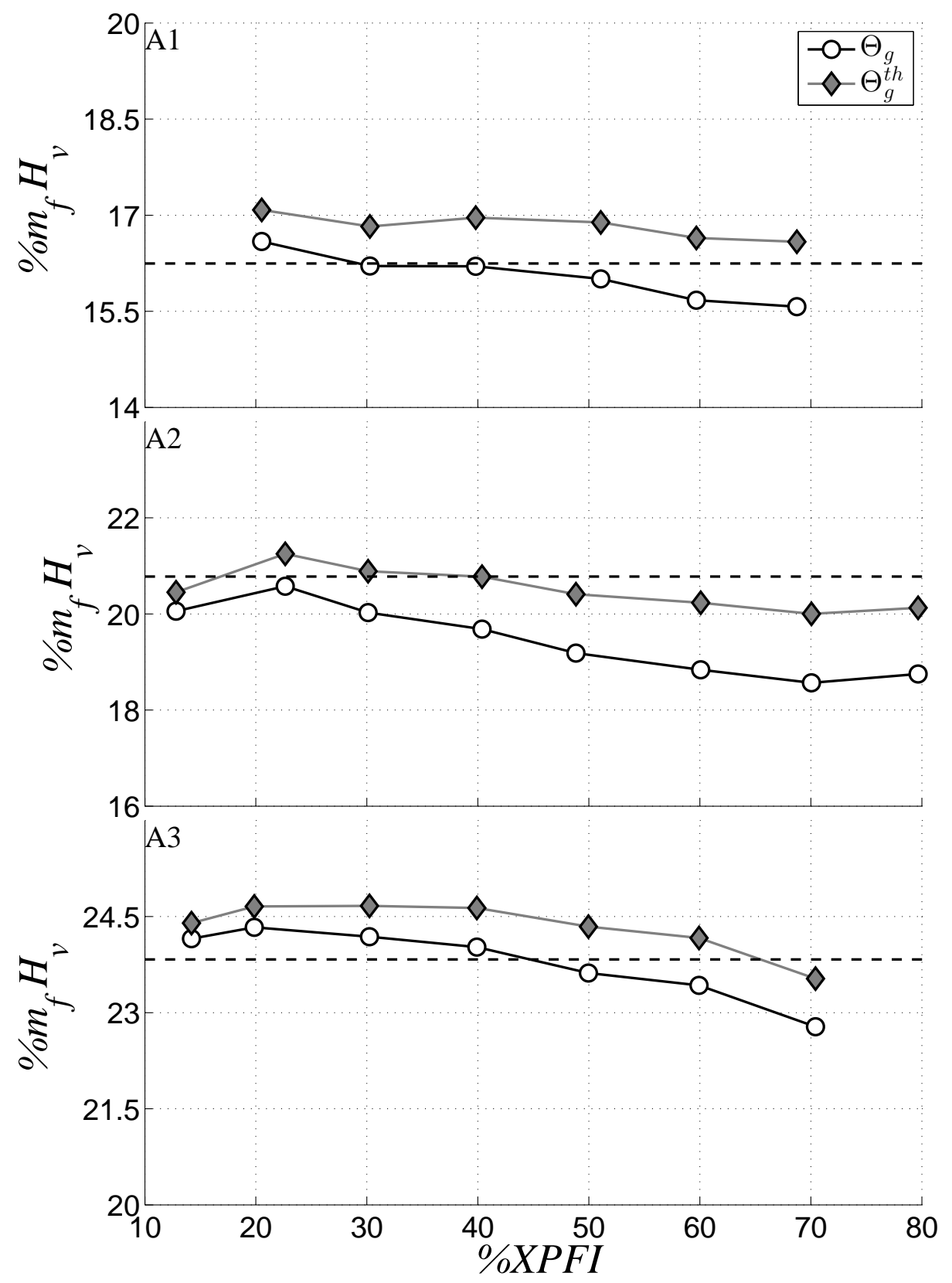

Figure 9: Net sensible exhaust enthalpy, CDC in dashed line 

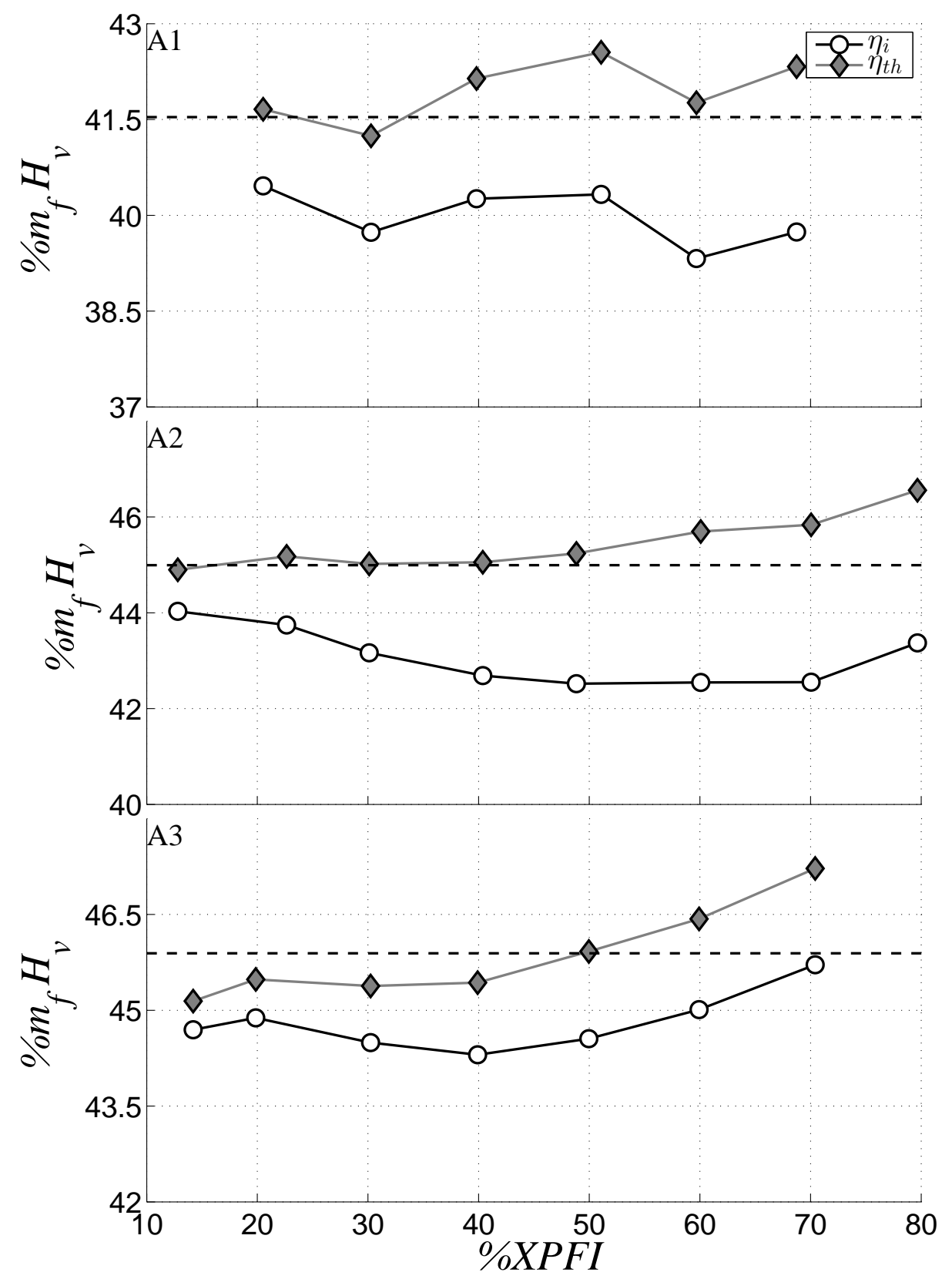

Figure 10: Indicated and thermal efficiencies, CDC in dashed line 


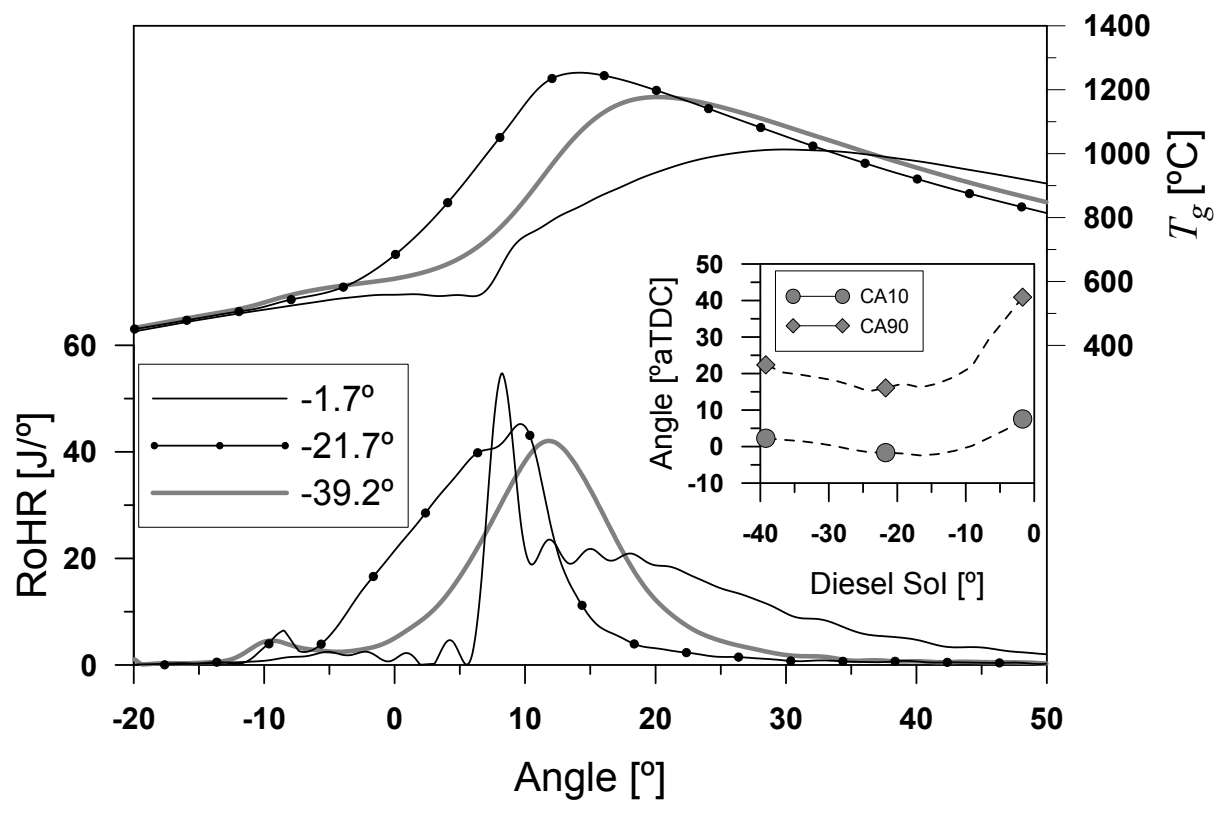

Figure 11: $T_{g}$ (top) and RoHR (bottom) for SoI variation at 90\%XPFI without EGR 


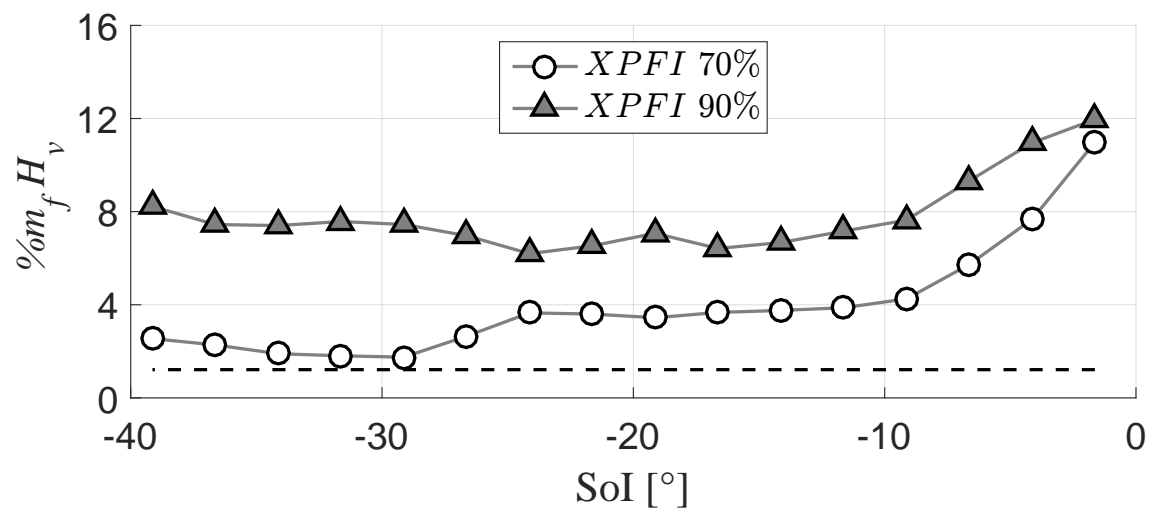

Figure 12: Incomplete combustion losses due to SoI variation, CDC in dashed line 


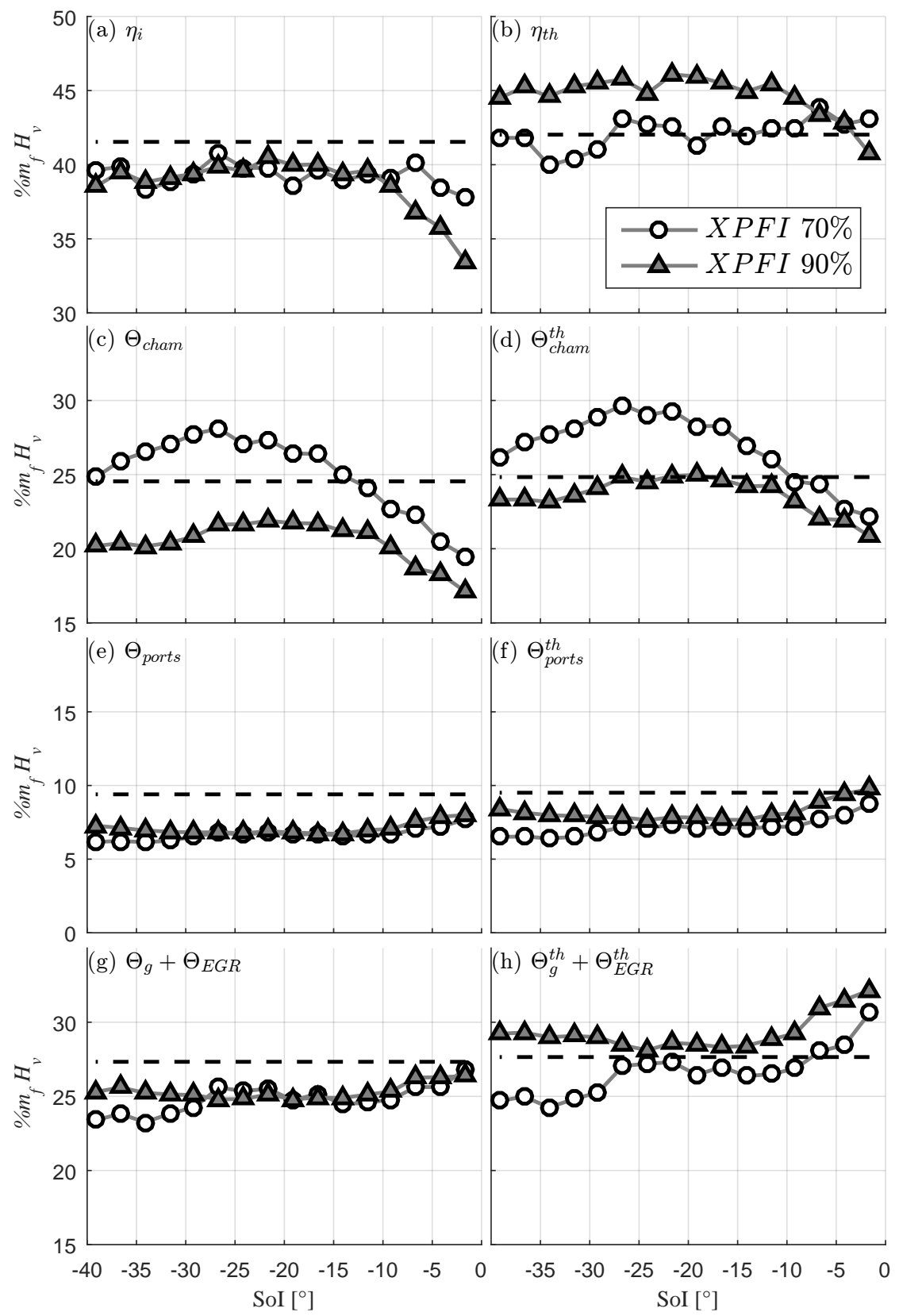

Figure 13: GEB for the SoI sweep, CDC in dashed line 


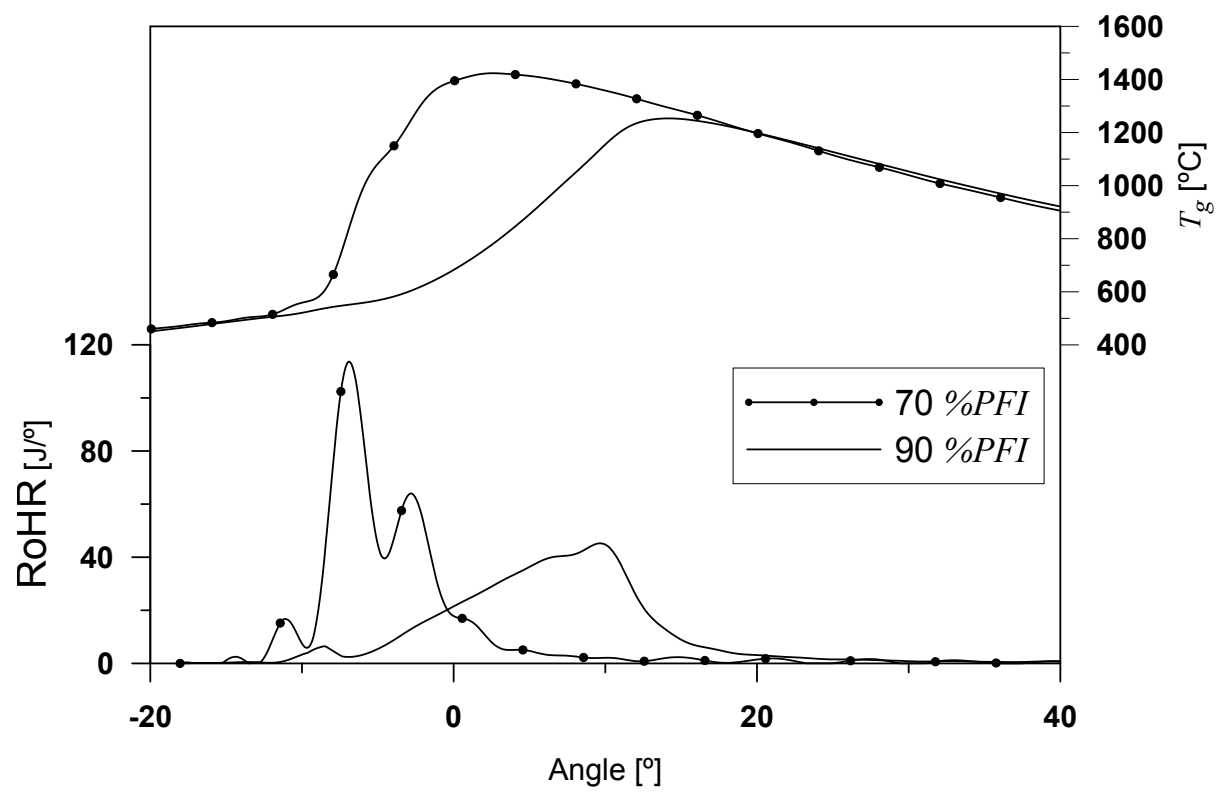

Figure 14: RoHR and $T$ variation due to changes in the $\%$ XPFI (SoI $-21^{\circ}$ aTDC) 


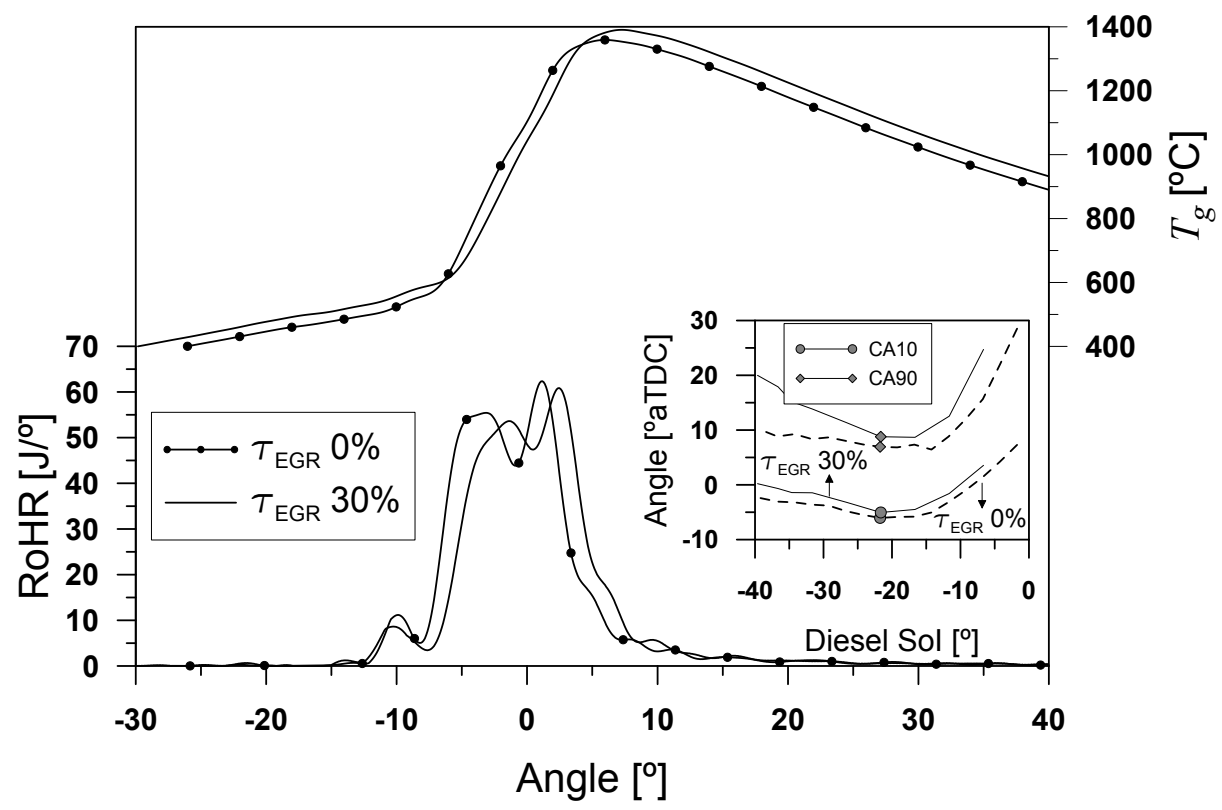

Figure 15: $T_{g}$ (top) and RoHR (bottom) for EGR variation at $80 \% X P F I$ and $\mathrm{SoI}=-21.2^{\circ}$ 


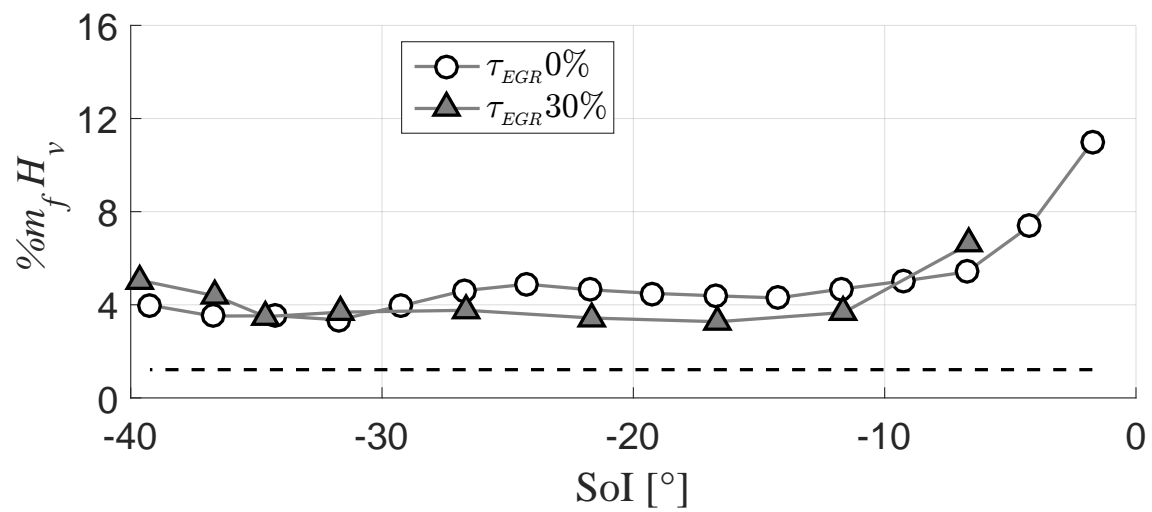

Figure 16: Incomplete combustion losses due to EGR variation, $\mathrm{CDC}$ in dashed line 


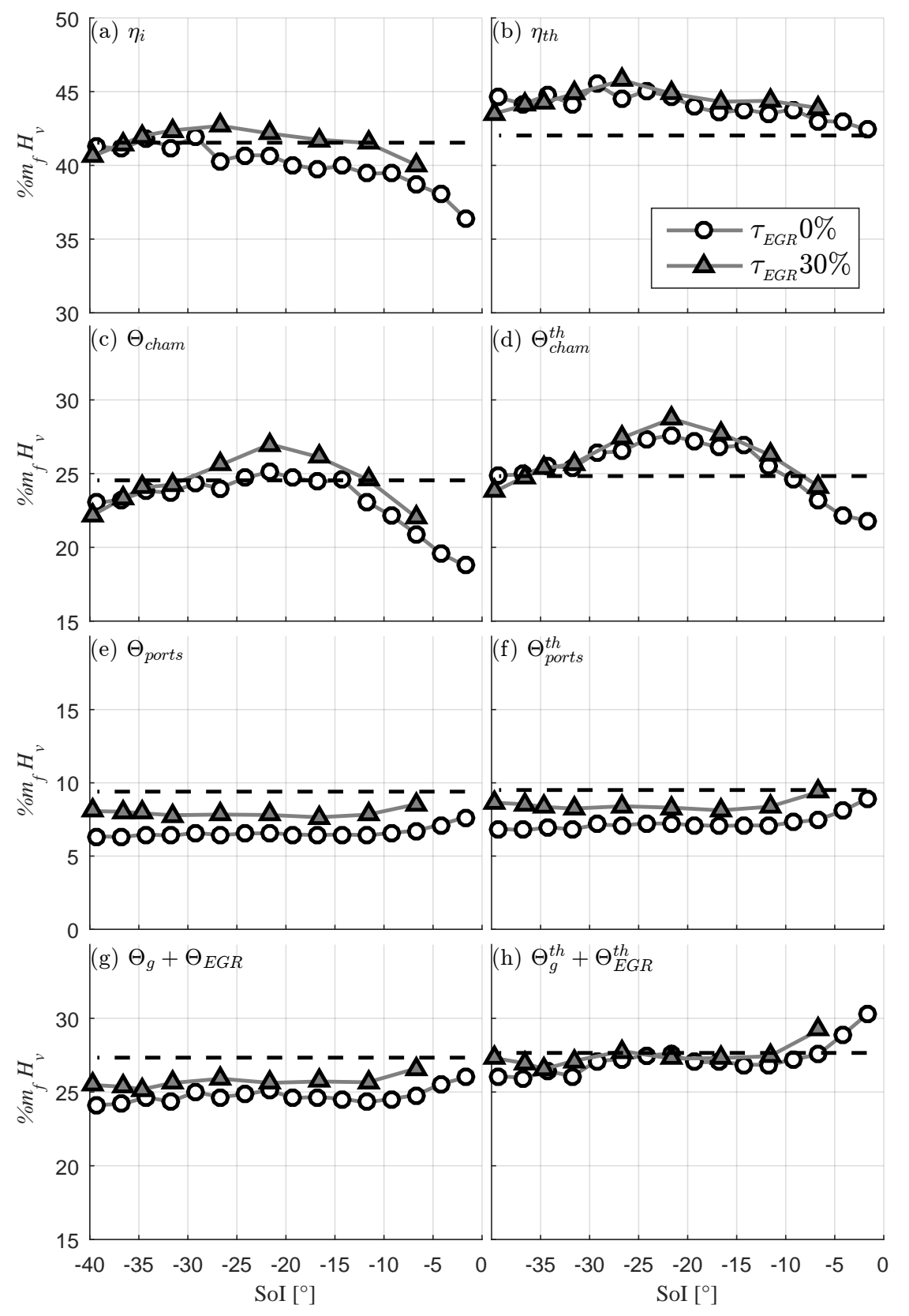

Figure 17: GEB for the EGR sweep, CDC in dashed line 